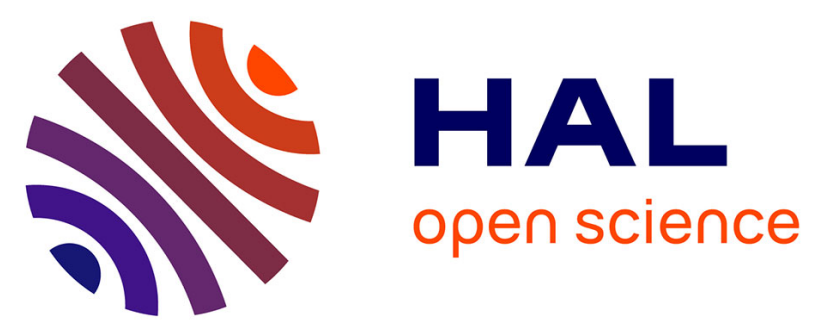

\title{
Mineralogical survey of the anorthositic Feldspathic Highlands Terrane crust using Moon Mineralogy Mapper data
}

M. Martinot, Jessica Flahaut, S. Besse, C. Quantin-Nataf, W. van Westrenen

\section{- To cite this version:}

M. Martinot, Jessica Flahaut, S. Besse, C. Quantin-Nataf, W. van Westrenen. Mineralogical survey of the anorthositic Feldspathic Highlands Terrane crust using Moon Mineralogy Mapper data. Icarus, 2020, 345, pp.113747. 10.1016/j.icarus.2020.113747 . hal-02530351

\section{HAL Id: hal-02530351 \\ https://hal.science/hal-02530351}

Submitted on 27 Aug 2020

HAL is a multi-disciplinary open access archive for the deposit and dissemination of scientific research documents, whether they are published or not. The documents may come from teaching and research institutions in France or abroad, or from public or private research centers.
L'archive ouverte pluridisciplinaire HAL, est destinée au dépôt et à la diffusion de documents scientifiques de niveau recherche, publiés ou non, émanant des établissements d'enseignement et de recherche français ou étrangers, des laboratoires publics ou privés.

\section{(c)(1)}

Distributed under a Creative Commons Attribution| 4.0 International License 


\title{
Mineralogical survey of the anorthositic Feldspathic Highlands Terrane crust using Moon Mineralogy Mapper data
}

\author{
M. Martinot ${ }^{\mathrm{a}, \mathrm{b}, *}$, J. Flahaut $^{\mathrm{c}}$, S. Besse ${ }^{\mathrm{d}}$, C. Quantin-Nataf ${ }^{\mathrm{b}}$, W. van Westrenen ${ }^{\mathrm{a}}$ \\ ${ }^{a}$ Faculty of Science, Vrije Universiteit Amsterdam, De Boelelaan 1085, 1081 HV Amsterdam, The Netherlands \\ ${ }^{\mathrm{b}}$ UMR CNRS 5276 LGLTPE, Université Claude-Bernard Lyon 1, Lyon 69622, France \\ ${ }^{\mathrm{c}}$ Centre de Recherches Pétrographiques et Géochimiques, CNRS/Université de Lorraine F-54500, Vandoeuvre-lès-Nancy, France \\ ${ }^{\mathrm{d}}$ European Space Astronomy Centre, P.O. Box 78, 28691 Villanueva de la Canada, Madrid, Spain
}

\section{A R T I C L E I N F O}

\section{Keywords:}

Feldspathic Highlands Terrane

Moon Mineralogy Mapper

Spectroscopy

\begin{abstract}
A B S T R A C T
Spectroscopic data from the Moon Mineralogy Mapper $\left(\mathrm{M}^{3}\right)$ instrument are used to study the mineralogy of the central peak or peak ring of 75 craters located in the lunar anorthositic Feldspathic Highlands Terrane (FHT-a), as defined by Jolliff et al. (2000). The thickness of South-Pole Aitken (SPA) ejecta at the location of the selected craters is estimated. Crustal thickness models are used with empirical cratering equations to estimate the depth of origin of the material excavated in the studied central peaks, and its distance to the crust-mantle interface. The goal of this survey is to study the composition of the FHT-a crust, and the extent of its potential lateral and vertical heterogeneities. High-Calcium Pyroxene (HCP) and featureless spectra are mostly detected throughout the entire FHT-a, whereas the number of pure plagioclase detections is small. No relationship between the central peak composition and the distance to SPA or the depth within the SPA ejecta is observed. The SPA ejecta material cannot be spectrally distinguished from crustal material. We interpret the paucity of plagioclase spectra in the FHT-a, which contrasts with more frequent plagioclase detections in the central peaks of craters sampling the crust in younger lunar terranes using identical spectroscopic techniques Martinot et al. (2018b), as a possible effect of terrane maturation, or of mixing with mafic components that mask their signature in the visible near-infrared. Overall, the FHT-a appears homogeneous laterally. However, data hint at a pyroxene compositional change with increasing depth, from high-calcium content in the upper crust towards less calcic compositions with increasing depth, which is consistent with prior studies of the architecture of the lunar crust.
\end{abstract}

\section{Introduction}

Studying the lunar surface composition and mineralogy can provide constraints on the Moon's magmatic and thermal evolution (e.g., Shearer et al., 2006; Jaumann et al., 2012). An asymmetry between the nearside and the farside surface was first observed on the images retrieved from the early Luna missions. Analyses of the Lunar Prospector geochemical data showed that there is a geographic link between the surface abundance of heat-producing elements and the location of basaltic maria (Lawrence et al., 1998). Jolliff et al. (2000) divided the lunar surface into three major terranes based on Clementine multispectral data and global geochemical data provided by the Lunar Prospector gamma-ray spectrometer (Fig. 1). The Procellarum KREEP Terrane (PKT) includes the nearside high-thorium region; the South-Pole Aitken Terrane (SPAT) comprises the farside high average $\mathrm{FeO}$ non-mare material. The Feldspathic Highlands Terrane (FHT) is anorthositic, and characterized by low $\mathrm{FeO}$ and thorium abundances.
The FHT is further subdivided into two sub-terranes, based on their geochemical signature: the FHT-a, highly anorthositic and covering most of the lunar farside outside the SPAT, and the outer FHT (FHT-o), including cryptomare and impact basins ejecta.

The lunar nearside-farside asymmetry is not limited to the lunar surface. A $2 \mathrm{~km}$ offset towards the Earth of the Moon center of mass relative to the center of figure was observed (Bills and Ferrari, 1977; Kaula, 1979). The crustal thickness models derived from the Clementine mission data suggested that the farside had a higher average crustal thickness $(68 \mathrm{~km})$ than the nearside crust $(60 \mathrm{~km})$ (Zuber et al., 1994). More recently, data from the Gravity Recovery and Interior Laboratory (GRAIL, Wieczorek et al. (2013)) confirmed that the FHT has a higher average crustal thickness than the SPAT and the PKT (36 km for the FHT and $27 \mathrm{~km}$ for the SPAT and the PKT), but with lower average values than previously estimated from Clementine data.

\footnotetext{
* Corresponding author at: Faculty of Science, Vrije Universiteit Amsterdam, De Boelelaan 1085, 1081 HV Amsterdam, The Netherlands. E-mail address: m.martinot@vu.nl (M. Martinot).
} 


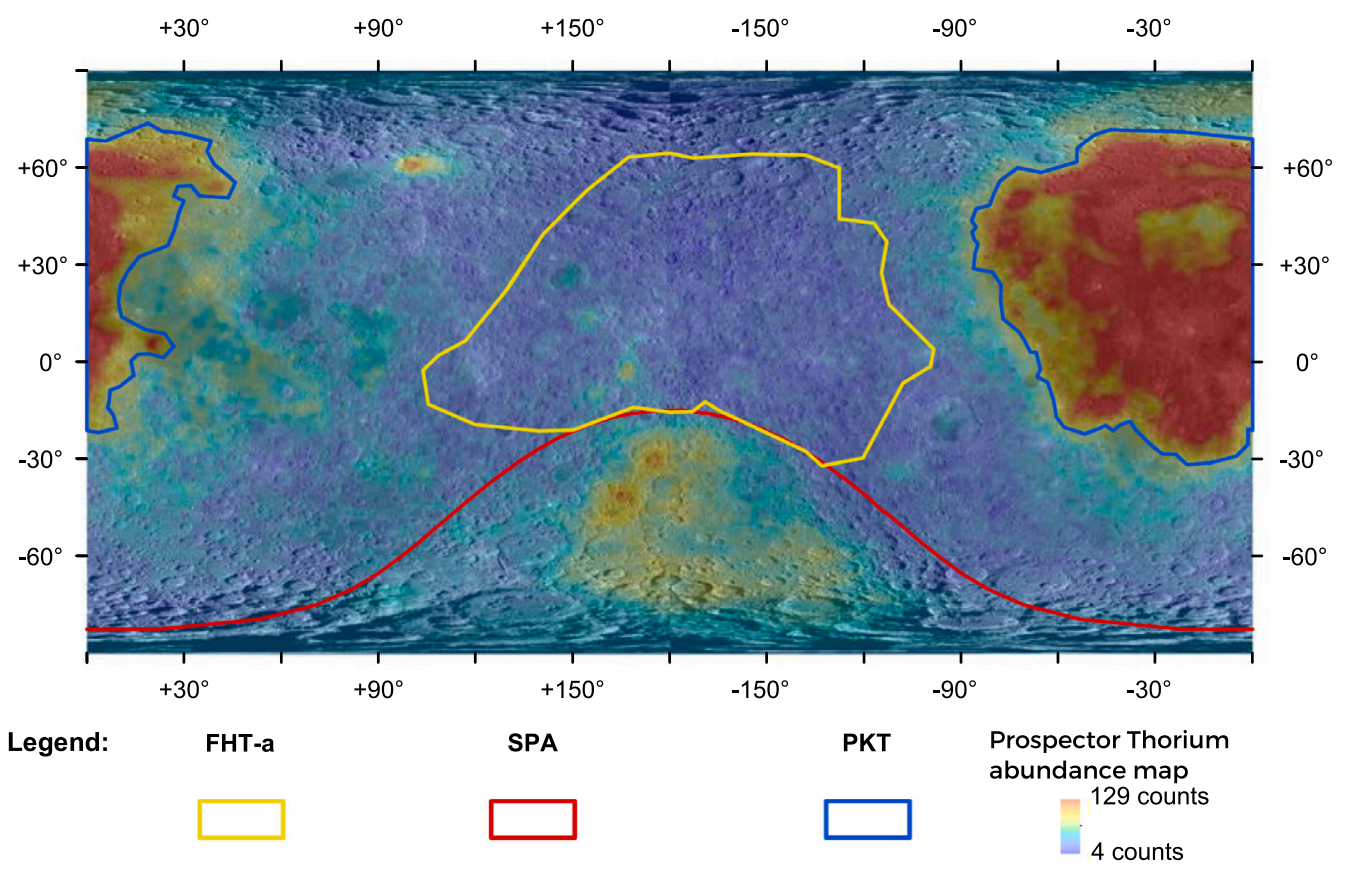

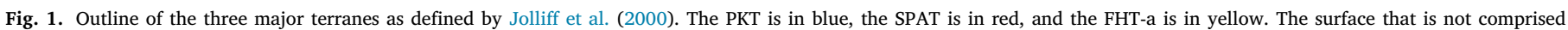

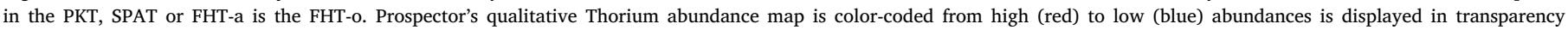

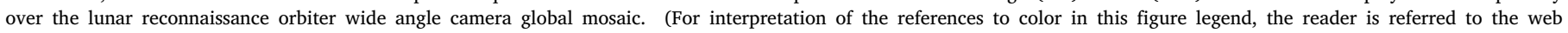
version of this article.)

Different lunar evolution models were proposed to explain the nearside-farside asymmetry. Hypotheses include: an asymmetric crystallization of the magma ocean (Wasson and Warren, 1980; Ohtake et al., 2012; Charlier et al., 2018); the asymmetric accumulation of a liquid iron alloy, resulting in the displacement of the colder, undifferentiated core upwards (Stevenson, 1980); or the result of a gravitational instability that triggered the preferential emplacement of lunar mare on the nearside (Parmentier et al., 2002). Yamamoto et al. (2016) proposed that a two-stage crustal growth could explain the observed discrepancy between thorium abundance and crustal thickness. The authors proposed that low-thorium floating plagioclase plateaus crystallized and aggregated to form a lid on the surface of the magma ocean, followed by a downward growth of the lunar crust. More recently, Laneuville et al. (2018) proposed a thermal evolution model in which the mantle beneath the PKT is moderately enriched in heat producing elements compared to the mantle beneath the highlands, resulting in a slower cooling of some parts of the PKT. This asymmetry influences the temperature of the mantle, thus able to sustain a volcanic activity on the nearside for longer than on the farside.

A number of remote sensing studies have surveyed the mineralogy of the farside-centered FHT to further elucidate the nearside-farside asymmetry. Lucey and Cahill (2006) and Arai et al. (2008) combined geochemical data with remote sensing studies, and proposed that the lunar nearside crust is composed of ferroan anorthosites, whereas the farside crust (and presumably the FHT-a) is composed of more magnesian material. As a consequence, and based on the cumulate sequence where high- $\mathrm{Mg}$ rocks crystallize before lower $\mathrm{Mg}$ rocks, Arai et al. (2008) proposed a two-stage crystallization for the Lunar Magma Ocean with the crystallization of the troctolitic farside crust prior to that of the noritic nearside. An extended age range and overlap is observed between lunar anorthosites and magnesian suite plutonic rocks (e.g., Papanastassiou and Wasserburg, 1971b,a; Borg et al., 1999; Gross et al., 2014; Borg et al., 2015). Gross et al. (2014) proposed that this age overlap is expected in the case of serial magmatism, where basaltic magmas intrude the crust, differentiate and form anorthosite diapirs.

Various remote sensing surveys have investigated the composition of the lunar crust at depth using impact craters as natural, vertical probes in the lunar interior, and using visible near-infrared (VNIR) observations in order to study the global distribution of anorthosite. Previous authors concluded on the existence of a global, but discrete, $\sim 30$ to $50 \mathrm{~km}$ thick layer of nearly pure anorthosite buried under a 3 to $10 \mathrm{~km}$ thick more pyroxene-rich mixed layer resulting from impact events (Hawke et al., 2003; Ohtake et al., 2009; Yamamoto et al., 2012a; Donaldson Hanna et al., 2014). Hawke et al. (2003) described these pure anorthosites (PAN) as rocks with over 95 vol.\% plagioclase. Ohtake et al. (2009), Yamamoto et al. (2012a) and Donaldson Hanna et al. (2014) reported the presence of PAN exposures specifically in the FHT.

Farside crust studies however need to take into account the effects of the formation of the South-Pole Aitken basin, which is the largest impact structure on the Moon (e.g., Stuart-Alexander, 1978; Wilhelms et al., 1979). According to Arai et al. (2008), the FHT was significantly resurfaced by the SPA basin formation, and post-magma ocean magmatism.

The SPA basin itself shows geochemical and mineralogical zonations (e.g., Jolliff et al., 2000; Moriarty and Pieters, 2018). Yamamoto et al. (2012b) studied the distribution of olivine in the SPA basin with spectroscopic data, and reported a paucity of olivine exposures in the SPA basin. Moriarty et al. (2013) and Moriarty and Pieters (2018) studied the SPA basin with spectroscopic data from $\mathrm{M}^{3}$ and showed that the composition of the basin is organized in concentric annuli, from pyroxene-rich signatures in its center to more anorthositic-rich signatures towards the SPA exterior. Melosh et al. (2017) modeled the formation of the SPA basin, and showed that it must have sampled the lunar upper mantle. The lack of olivine detections in and around SPA, combined with the abundance of Low-Calcium Pyroxene (LCP) led them to conclude that the upper mantle of the Moon is LCP-rich, although alternative studies proposed that LCP signatures in SPA could be associated to a differentiated impact melt sheet (e.g., Moriarty and Pieters (2018)).

According to the Lunar Magma Ocean (LMO) concept, the lunar crust was formed by flotation of plagioclase after approximately $70 \%$ of the magma ocean crystallized, whereas denser, mafic cumulates of olivine and pyroxene minerals sank to the bottom of the magma ocean, 
forming the lunar mantle (e.g., Smith et al., 1970; Wood, 1970; Warren, 1985; Lin et al., 2017a). This concept is supported by a range of recent experimental studies of LMO crystallization (Lin et al., 2017a,b; Charlier et al., 2018; Rapp and Draper, 2018; Lin et al., 2020). Some authors proposed that the mafic content of the crust builds up with increasing depth (Ryder and Wood, 1977; Spudis and Davis, 1986; Tompkins and Pieters, 1999; Cahill et al., 2009), while observations from other authors debate this conclusion (Song et al., 2013; Lemelin et al., 2015). Martinot et al. (2018b) found in their study of craters located in the PKT and FHT terranes that crustal pyroxene composition changes with increasing depth, from HCP towards LCP. However, they did not find a clear mineralogical transition between the presumed crustal and mantle material, as they detected plagioclase occurrences (implying the presence of $>95 \%$ plagioclase, Cheek et al. (2013)) in large craters supposedly sampling mantle material. In the present study, the mineralogical diversity of the FHT-a crustal column specifically is constrained. The goal of this work is to find out whether the FHT-a crust becomes more mafic with increasing depth, which could provide further constraints to lunar evolution models. The central peak or peak ring of 75 impact craters located within the FHT-a were studied with spectroscopic data from $\mathrm{M}^{3}$.

\section{Material and methods}

\subsection{Reflectance data and crater selection}

Reflectance data from the Moon Mineralogy Mapper $\left(\mathrm{M}^{3}\right)$ were used in order to derive the mineralogic diversity of the craters central peak or peak ring. $\mathrm{M}^{3}$ is a VNIR hyperspectral imager that orbited the Moon between 2008 and 2009. $\mathrm{M}^{3}$ data span 85 spectral channels, from 430 to $3000 \mathrm{~nm}$ (Pieters et al., 2009). The $\mathrm{M}^{3}$ data used here were archived in the Planetary Data System (PDS, version 1 of Level 2). These data are calibrated, and were corrected for radiometry, geometry, thermal effects and geometry (Green et al., 2011; Boardman et al., 2011; Clark et al., 2011; Besse et al., 2013). The mosaics were made with data from the same optical period OP2C2, with a spatial resolution of $280 \mathrm{~m} /$ pixel. The same optical period was used in order to keep similar detector conditions (i.e., beta angle, spacecraft altitude). The optical period OP2C2 was selected because it covers the maximum number of central peak or peak ring craters in the FHT-a. The Lunar Impact Crater Database (LICD) Losiak et al. (2009) (revised by Ohman at LPI) provides a list of lunar impact craters. To maximize the retrieval of information about the vertical and lateral architecture of the FHTa crust, all complex craters from the LICD located in the FHT-a, and which central peak or peak ring is partially or completely covered by the $\mathrm{M}^{3}$ OP2C2 optical period data, were selected for mineralogical study. A total of 75 craters were selected (Fig. 2, see Table A.3 in supplementary material).

Because of their low signal-to-noise ratio, $\mathrm{M}^{3}$ wavelengths below $620 \mathrm{~nm}$ were discarded (Green et al., 2011). Thermal effects due to the contribution of the lunar surface are significant at wavelengths beyond $2700 \mathrm{~nm}$ (Clark et al., 2011). Therefore, $\mathrm{M}^{3}$ reflectance data beyond $2700 \mathrm{~nm}$ were not analyzed.

The global Lunar Reconnaissance Orbiter (LRO) Wide Angle Camera (WAC) mosaic (spatial resolution of $100 \mathrm{~m} /$ pixel) was used in order to visualize the geological context of the central peaks. The LRO Lunar Orbiter Laser Altimeter (LOLA) global digital elevation model (horizontal precision: $118 \mathrm{~m}$ at the Equator, vertical precision: $1 \mathrm{~m}$ ) was used in order to provide information on the topography and elevation of the central peaks or peak rings (Smith et al., 2010).

The GRAIL mission acquired gravimetric data from the Moon between 2011 and 2012. Wieczorek et al. (2013) derived four crustal thickness models, assuming different crustal porosities and different initial crustal constraints thickness with Apollo 12 and 14 landing sites' seismic data. Here, the GRAIL crustal thickness model 1 was used in order to constrain crustal thickness values at each crater location as in our previous studies Martinot et al. (2018a,b), see Table A.3 in supplementary material. The GRAIL crustal thickness model 1 was chosen because it is the crust thickness model that is best supported by mineralogical observations in the earlier study from Martinot et al. (2018b).

\subsection{Data processing and pyroxene composition analysis}

The number of absorption bands and their position in $\mathrm{M}^{3}$ VNIR reflectance spectra enable the identification of several minerals. In this survey, plagioclase and High-Calcium Pyroxene (HCP) spectra were detected. Adams and Goullaud (1978) showed that the spectrum of iron-bearing plagioclase exhibits a single absorption band centered at $1250 \mathrm{~nm}$. HCP spectra are characterized by the presence two broad absorption bands centered around $1000 \mathrm{~nm}$ and 2200 to $2300 \mathrm{~nm}$ (Adams, 1974). Featureless spectra are spectra that do not exhibit absorption features and are interpreted to result from plagioclase losing their absorption feature due to shock pressures (Adams and Hörz, 1979), or anorthosite affected by space weathering (Lucey, 2002). Examples of these spectra can be found in Martinot et al. (2018b) (see Fig. 4).

Prior to mineral identification, $\mathrm{M}^{3}$ data were processed using the continuum-removal algorithm and output spectral parameter maps developed by Martinot et al. (2018a). With this algorithm, the spectral continuum is found by maximizing the absorption band area of lunar mafic minerals at 1000 and $2000 \mathrm{~nm}$. Tie points to the spectrum continuum are searched for in fixed intervals $(620-1100 \mathrm{~nm}$; 1100 $1660 \mathrm{~nm}$ ) on a spectrum previously smoothed using a moving average window of 3 spectral channels, in order to limit the influence of noise on the tie point positions. A third tie point is fixed at $2700 \mathrm{~nm}$. After continuum removal, the band positions are found by fitting the band minimum $\pm 200 \mathrm{~nm}$ with a 4 th order polynomial, and finding the minimum of this fit. The band depth is then calculated as $1-$ the reflectance of the band position.

Output parameter maps (e.g., band 1 and 2 position, depth, area, asymmetry) are computed on continuum-removed data and stretched in order to highlight the central peak or peak ring diversity. Full description of this method can be found in Martinot et al. (2018a). In this study, the band 1 position and the band 2 position and band 2 depth maps are primarily used. Only spectra with a band 2 depth stronger than $2 \%$ were considered for pyroxene compositional analyses, in order to limit the effect of noise. Pixels located in shadowed areas were also discarded, due to their low average reflectance (which could lead to a mis-interpretation of the mineralogical signature).

This specific continuum-removal algorithm is optimized for spectra displaying two absorption bands (e.g., pyroxene) because the algorithm looks for two absorption bands. Minerals displaying a single absorption band (e.g., plagioclase) can however also be processed correctly by the continuum-removal algorithm as the sum of both (when the two are present) absorption bands areas is maximized. For the purpose of this study, spectral parameters developed specifically for the detection of plagioclase were used in order to identify plagioclase occurrences on the selected central peaks. Two spectral parameters were used in order to identify plagioclase occurrences on the selected central peaks: the band depth at $1250 \mathrm{~nm}$ (BD1250, used by Donaldson Hanna et al. (2014)), and the $1250 \mathrm{~nm}$ integrated band depth (IBD1250). The BD1250 parameter calculates the band depth at $1250 \mathrm{~nm}$, by using continuum boundaries at 749 and $1579 \mathrm{~nm}$. This spectral parameter highlights plagioclase spectra with band depth exceeding 1-2\% (Donaldson Hanna et al., 2014). The IBD1250 parameter uses continuum boundaries at 1029 and $1698 \mathrm{~nm}$, and calculates the sum of 27 spectra channels band depths, starting at $1029 \mathrm{~nm}$ (Donaldson Hanna et al., 2014).

Moriarty et al. (2013) used scatter plots presenting band depth values as a function of band positions in order to assess pyroxene compositional variations within a central peak, and to obtain the degree 


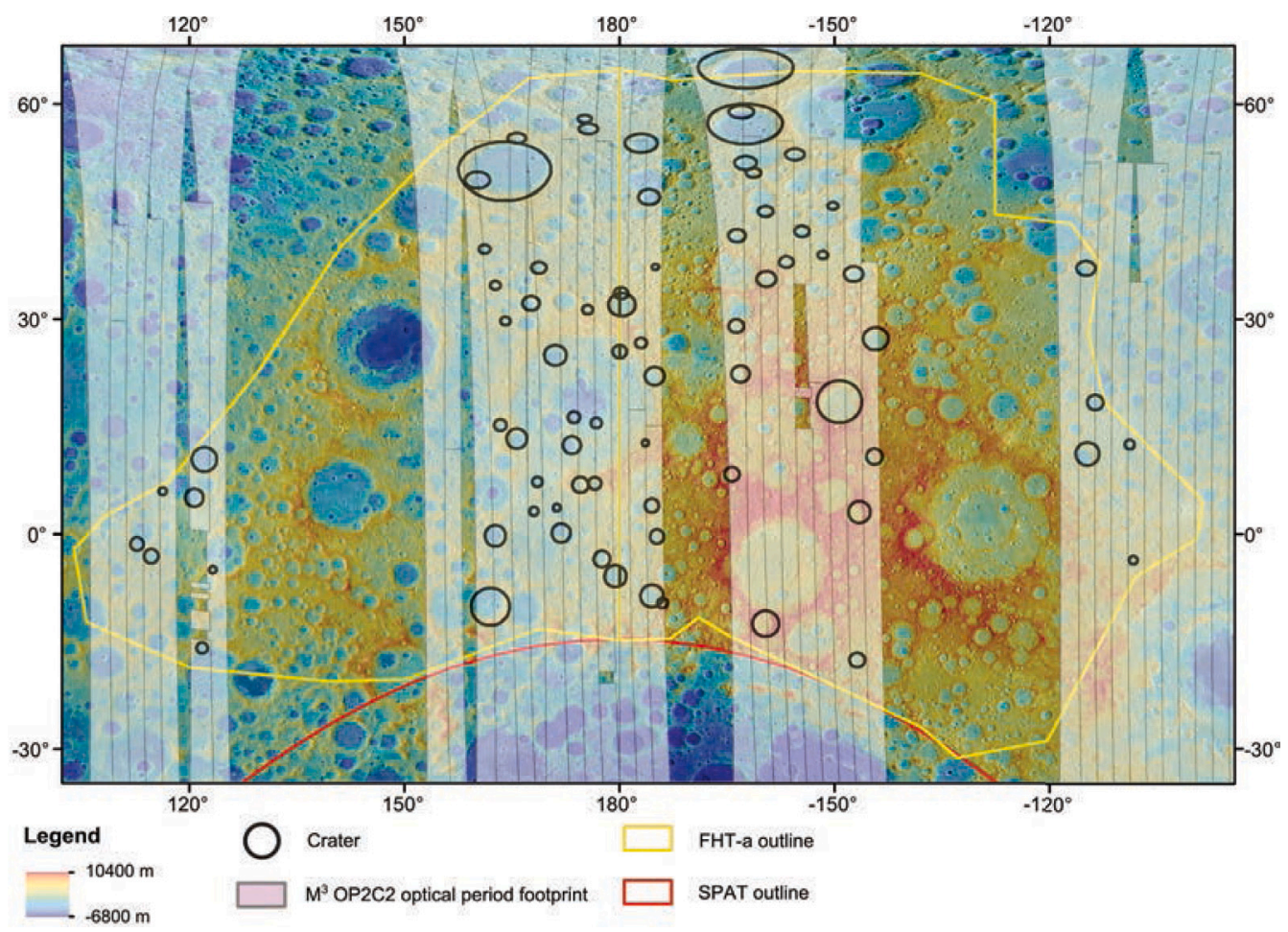

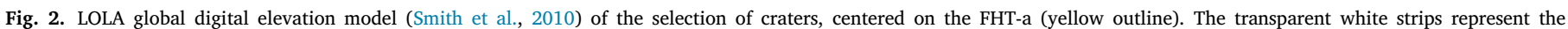

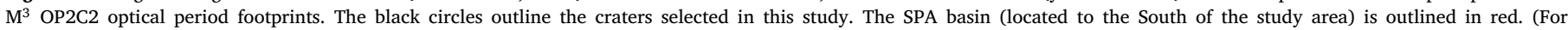
interpretation of the references to color in this figure legend, the reader is referred to the web version of this article.)

of homogeneity in a central peak. We used a similar method to study pyroxene compositional variations. In each central peak or peak ring crater, all spectra displaying a pyroxene signature (a band 1 center centered between $850 \mathrm{~nm}$ and $1100 \mathrm{~nm}$, and a band 2 center centered between $1700 \mathrm{~nm}$ and $2400 \mathrm{~nm}$ ) were selected. These output pixels are further referred to as the pixels in the central peak having a pyroxene signature.

In some craters, less than $10 \%$ of the pixels covering the central peak surface had a pyroxene signature. These craters were discarded from further analysis, as their central peak material could be very heterogeneous (e.g., if tapping in a pluton), or the exposures could be spatially restricted. For craters with more than $10 \%$ of central peak pixels showing pyroxene signature, the spectral dispersion of the pyroxene composition was assessed using the median position of the 200 pixels in each central peak having the strongest band depth. The arbitrary number 200 was determined empirically. In order to show the spread of data against wavelength, the minimum and maximum positions of the band 1 and 2 center are extracted from the data, as well as the minimum and maximum values of the band 1 and 2 depth values, and the distribution of those values (Table 1).

\subsection{SPA ejecta thickness calculation}

Given its large size, the SPA basin formation probably ejected material over the whole Moon; it is thus important to take the SPA basin ejecta into account when investigating the composition of the nearby FHT-a province. Several material transport models predict the thickness of ejected material at a given distance to an impact basin. Eqs. (1) and (2) describe the models from McGetchin et al. (1973) and Housen et al. (1983), respectively.

$$
\begin{aligned}
& T=0.14 \times R^{0.74} \times(r / R)^{-3}, \text { and } \\
& T=0.0078 \times R \times(r / R)^{-2.61}
\end{aligned}
$$

Estimates of SPA ejecta thickness at the location of the selected craters are noted $T$ (see Table A.3 in supplementary material). More complicated ejecta thickness calculations taking the asymmetry into account were not considered in our first-order approach. In both equations, the distance to SPA, noted $r$ was measured from the center of the SPA basin, in meters. The SPA basin diameter is noted $R$, in meters, and is taken to be $2600 \mathrm{~km}$ (Melosh, 2011). The model from McGetchin et al. (1973) gives an ejecta thickness that is 2 times lower than that of Housen et al. (1983) (4 to $74 \mathrm{~km}$ with McGetchin et al. (1973) equation, and 10 to $144 \mathrm{~km}$ with Housen et al. (1983) equation). We favor Eq. (1) in our final discussion in order to have a lower estimate for the thickness of ejecta.

\subsection{Proximity value to an interface}

The proximity value to an interface, introduced by Cahill et al. (2009), compares the distance of origin of the material emplaced in a crater central peak to a given interface (e.g., the crust-mantle interface). (Cintala and Grieve, 1998) proposed that the maximum depth of melting $\left(\mathrm{D}_{m}\right)$ can be approximated as the minimum depth of origin of central peak material. Two proximity values were calculated in this study (see Table A.3 in supplementary material): the proximity value to the interface between the SPA ejecta and the FHT-a crust, and the proximity value to the crust-mantle interface (referred to as $\mathrm{P}_{c m i}$ value). The proximity value to the interface between the SPA ejecta and the FHT-a crust (i.e., depth in the SPA ejecta) is noted $\mathrm{D}_{S P A}^{*}$ when calculated using Eq. (1), and $\mathrm{D}_{S P A}^{* *}$ when calculated using Eq. (2). The thickness of the crust before the impact event was calculated following the method in Flahaut et al. (2012). The crustal thickness of an annulus around the impact crater was averaged, at a distance of one crater diameter, $\pm 10 \%$ of the crater diameter. The GRAIL crustal thickness model 1 was used to provide crustal thickness values (Wieczorek et al., 2013) for the proximity value to the crust-mantle interface. If the $P_{c m i}$ value is positive, only crustal material should be chemically represented in the central peak; if the $\mathrm{P}_{c m i}$ value is negative, then material from below the crust-mantle interface is potentially emplaced in the central peak material. 
Table 1

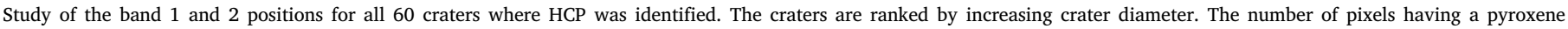

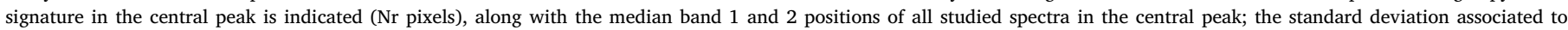

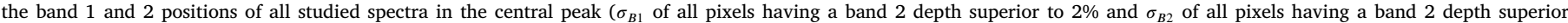

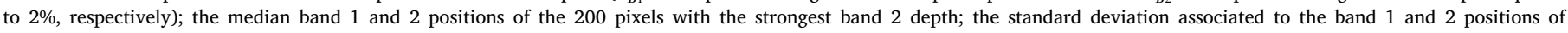

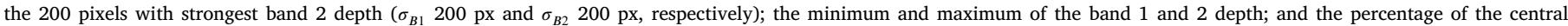

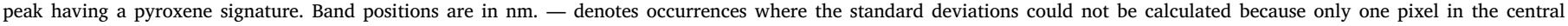
peak has a band 2 depth superior to $2 \%$.

\begin{tabular}{|c|c|c|c|c|c|c|c|c|c|c|c|c|c|c|c|}
\hline Crater & $\begin{array}{l}\mathrm{Nr} \text { pixels } \\
\text { total in } \mathrm{CP}\end{array}$ & $\begin{array}{l}\mathrm{Nr} \\
\text { pixels }\end{array}$ & $\begin{array}{l}\% \mathrm{CP} \\
\text { covered }\end{array}$ & $\begin{array}{l}\text { Median B1 } \\
\text { sup. } 2 \%\end{array}$ & $\begin{array}{l}\text { Median B2 } \\
\text { sup. } 2 \%\end{array}$ & $\begin{array}{l}\sigma B 1 \\
\text { sup. } 2 \%\end{array}$ & $\begin{array}{l}\sigma B 2 \\
\text { sup. } 2 \%\end{array}$ & $\begin{array}{l}\text { Median B1 } \\
200 \text { pix }\end{array}$ & $\begin{array}{l}\text { Median B2 } \\
200 \text { pix }\end{array}$ & $\begin{array}{l}\sigma B 1 \\
200 \text { pix }\end{array}$ & $\begin{array}{l}\sigma B 2 \\
200 \text { pix }\end{array}$ & $\begin{array}{l}\text { BD1 } \\
\min \end{array}$ & $\begin{array}{l}\mathrm{BD} 1 \\
\max \end{array}$ & $\begin{array}{l}\mathrm{BD} 2 \\
\min \end{array}$ & $\begin{array}{l}\mathrm{BD} 2 \\
\max \end{array}$ \\
\hline King & 25181 & 24693 & 98.1 & 950 & 2138 & 17.5 & 51.0 & 930 & 2138 & 28.5 & 70.8 & 0.00 & 0.21 & 0.02 & 0.20 \\
\hline Necho & 10090 & 9666 & 95.8 & 950 & 2098 & 22.4 & 71.2 & 950 & 2178 & 34.4 & 127.8 & 0.00 & 0.13 & 0.02 & 0.11 \\
\hline Ohm & 10791 & 9877 & 91.5 & 990 & 2218 & 15.2 & 31.8 & 970 & 2218 & 21.9 & 40.6 & 0.00 & 0.16 & 0.02 & 0.11 \\
\hline Moore F & 2772 & 2510 & 90.5 & 990 & 2258 & 17.9 & 40.4 & 990 & 2298 & 32.0 & 28.6 & 0.00 & 0.10 & 0.02 & 0.07 \\
\hline Montgolfier $\mathrm{Y}$ & 73 & 63 & 86.3 & 910 & 2178 & 20.4 & 42.8 & 910 & 2178 & 20.4 & 42.8 & 0.01 & 0.03 & 0.02 & 0.04 \\
\hline Larmor Z & 3061 & 2370 & 77.4 & 950 & 2178 & 46.3 & 53.2 & 930 & 2218 & 46.8 & 57.0 & 0.00 & 0.05 & 0.02 & 0.07 \\
\hline Tsinger $\mathrm{Y}$ & 1840 & 1293 & 70.3 & 930 & 2098 & 20.0 & 113.8 & 930 & 2058 & 23.5 & 139.2 & 0.01 & 0.24 & 0.02 & 0.16 \\
\hline d'Alembert Z & 1256 & 844 & 67.2 & 910 & 2058 & 26.7 & 89.9 & 930 & 2018 & 22.6 & 116.3 & 0.01 & 0.10 & 0.02 & 0.09 \\
\hline Tsinger & 230 & 84 & 36.5 & 910 & 2138 & 35.0 & 148.3 & 910 & 2138 & 35.0 & 148.3 & 0.01 & 0.05 & 0.02 & 0.05 \\
\hline Delporte & 847 & 256 & 30.2 & 950 & 2098 & 46.5 & 114.8 & 950 & 2098 & 35.5 & 121.4 & 0.00 & 0.05 & 0.02 & 0.05 \\
\hline d'Alembert & 21643 & 6076 & 28.1 & 890 & 2018 & 75.8 & 139.6 & 890 & 1978 & 73.5 & 132.3 & -0.01 & 0.20 & 0.02 & 0.08 \\
\hline Rowland $\mathrm{J}$ & 20876 & 4376 & 21.0 & 930 & 2178 & 35.6 & 95.7 & 910 & 2178 & 33.8 & 132.9 & 0.00 & 0.15 & 0.02 & 0.11 \\
\hline Golovin & 2569 & 437 & 17.0 & 930 & 2098 & 75.6 & 109.5 & 950 & 2098 & 76.7 & 111.1 & 0.00 & 0.03 & 0.02 & 0.05 \\
\hline Coriolis W & 6905 & 1077 & 15.6 & 930 & 2018 & 27.4 & 72.8 & 930 & 2018 & 33.8 & 100.9 & 0.00 & 0.09 & 0.02 & 0.06 \\
\hline Woltjer & 6390 & 961 & 15.0 & 910 & 2178 & 41.7 & 79.3 & 910 & 2218 & 50.7 & 94.6 & 0.00 & 0.08 & 0.02 & 0.06 \\
\hline Slipher & 13719 & 2058 & 15.0 & 890 & 2058 & 74.2 & 116.9 & 890 & 1978 & 77.0 & 117.9 & -0.01 & 0.05 & 0.02 & 0.05 \\
\hline Jackson & 18414 & 2589 & 14.1 & 990 & 2138 & 25.5 & 110.4 & 1010 & 2218 & 26.4 & 118.4 & 0.00 & 0.14 & 0.02 & 0.09 \\
\hline Stearns & 6421 & 811 & 12.6 & 930 & 2138 & 38.2 & 53.4 & 910 & 2178 & 47.7 & 62.0 & 0.00 & 0.07 & 0.02 & 0.06 \\
\hline Kulik J & 7124 & 897 & 12.6 & 910 & 2218 & 69.2 & 135.9 & 910 & 2218 & 73.0 & 183.8 & 0.00 & 0.05 & 0.02 & 0.05 \\
\hline Evershed C & 7013 & 744 & 10.6 & 930 & 2258 & 76.8 & 46.0 & 930 & 2258 & 75.1 & 44.5 & -0.01 & 0.03 & 0.02 & 0.04 \\
\hline Vesalius & 11928 & 1137 & 9.5 & 930 & 2138 & 39.1 & 45.1 & 950 & 2138 & 46.9 & 62.4 & -0.01 & 0.08 & 0.02 & 0.08 \\
\hline Buisson & 12792 & 1196 & 9.3 & 990 & 2098 & 55.8 & 56.4 & 990 & 2098 & 67.3 & 54.7 & 0.00 & 0.11 & 0.02 & 0.09 \\
\hline Katchalsky & 13465 & 1012 & 7.5 & 930 & 2138 & 65.4 & 61.0 & 950 & 2138 & 56.5 & 69.7 & 0.01 & 0.06 & 0.02 & 0.04 \\
\hline Rowland Y & 6779 & 489 & 7.2 & 910 & 2058 & 24.3 & 82.9 & 910 & 2058 & 26.3 & 98.6 & 0.01 & 0.11 & 0.02 & 0.06 \\
\hline Petropavlovskiy & 5073 & 364 & 7.2 & 930 & 2138 & 20.6 & 49.4 & 910 & 2138 & 22.4 & 53.6 & 0.00 & 0.06 & 0.02 & 0.05 \\
\hline Fowler W & 2703 & 133 & 4.9 & 910 & 2258 & 32.7 & 92.2 & 910 & 2258 & 32.7 & 92.2 & 0.00 & 0.04 & 0.02 & 0.04 \\
\hline Evershed & 4942 & 208 & 4.2 & 910 & 2178 & 42.9 & 84.1 & 910 & 2178 & 43.5 & 83.6 & 0.00 & 0.03 & 0.02 & 0.04 \\
\hline Butlerov & 6744 & 270 & 4.0 & 970 & 2178 & 13.6 & 60.7 & 970 & 2138 & 13.0 & 60.0 & 0.01 & 0.05 & 0.02 & 0.04 \\
\hline Nusl & 5857 & 218 & 3.7 & 930 & 2098 & 20.2 & 83.7 & 930 & 2098 & 20.9 & 80.5 & 0.00 & 0.08 & 0.02 & 0.07 \\
\hline Sharonov & 21480 & 704 & 3.3 & 970 & 2178 & 38.3 & 74.7 & 970 & 2218 & 43.8 & 60.7 & -0.01 & 0.07 & 0.02 & 0.07 \\
\hline Vening Meinesz & 12106 & 379 & 3.1 & 990 & 2138 & 77.0 & 109.8 & 1050 & 2178 & 67.2 & 126.8 & 0.00 & 0.03 & 0.02 & 0.04 \\
\hline Joule & 11851 & 265 & 2.2 & 970 & 2098 & 37.0 & 84.7 & 970 & 2138 & 40.3 & 87.6 & 0.00 & 0.04 & 0.02 & 0.05 \\
\hline Larmor & 9516 & 178 & 1.9 & 1010 & 2258 & 54.4 & 80.1 & 1010 & 2258 & 54.4 & 80.1 & 0.00 & 0.07 & 0.02 & 0.06 \\
\hline Doppler & 14383 & 268 & 1.9 & 970 & 2218 & 55.9 & 43.7 & 950 & 2218 & 52.3 & 44.6 & 0.00 & 0.03 & 0.02 & 0.05 \\
\hline Grachev & 7844 & 131 & 1.7 & 970 & 2138 & 13.3 & 48.1 & 970 & 2138 & 13.3 & 48.1 & 0.01 & 0.05 & 0.02 & 0.04 \\
\hline Dufay X & 3340 & 50 & 1.5 & 890 & 2018 & 22.8 & 93.5 & 890 & 2018 & 22.8 & 93.5 & 0.01 & 0.06 & 0.02 & 0.03 \\
\hline Cockcroft N & 11854 & 142 & 1.2 & 1010 & 2297 & 68.8 & 60.8 & 1010 & 2297 & 68.8 & 60.8 & 0.00 & 0.03 & 0.02 & 0.03 \\
\hline Chappell & 393 & 4 & 1.0 & 870 & 2258 & 0.0 & 23.1 & 870 & 2258 & 0.0 & 23.1 & 0.02 & 0.03 & 0.02 & 0.02 \\
\hline Artemev & 5268 & 52 & 1.0 & 990 & 2138 & 20.6 & 29.9 & 990 & 2138 & 20.6 & 29.9 & 0.01 & 0.06 & 0.02 & 0.06 \\
\hline Mach & 35098 & 314 & 0.9 & 970 & 2178 & 34.3 & 47.2 & 970 & 2218 & 40.5 & 45.8 & 0.00 & 0.03 & 0.02 & 0.04 \\
\hline Tiselius & 11345 & 100 & 0.9 & 990 & 2138 & 10.7 & 60.9 & 990 & 2138 & 10.7 & 60.9 & 0.01 & 0.06 & 0.02 & 0.05 \\
\hline Hutton & 1432 & 12 & 0.8 & 970 & 1818 & 64.5 & 164.6 & 970 & 1818 & 64.5 & 164.6 & 0.00 & 0.02 & 0.02 & 0.02 \\
\hline DanteE & 6714 & 53 & 0.8 & 1010 & 2218 & 60.7 & 96.7 & 1010 & 2218 & 60.7 & 96.7 & 0.00 & 0.03 & 0.02 & 0.03 \\
\hline Ostwald & 9801 & 72 & 0.7 & 950 & 2098 & 30.5 & 109.0 & 950 & 2098 & 30.5 & 109.0 & 0.00 & 0.07 & 0.02 & 0.03 \\
\hline Kolhorster & 11689 & 79 & 0.7 & 970 & 2098 & 16.6 & 28.2 & 970 & 2098 & 16.6 & 28.2 & 0.02 & 0.10 & 0.02 & 0.08 \\
\hline Perkin & 8916 & 58 & 0.7 & 950 & 2138 & 47.6 & 202.4 & 950 & 2138 & 47.6 & 202.4 & 0.01 & 0.05 & 0.02 & 0.04 \\
\hline Shayn H & 5452 & 35 & 0.6 & 990 & 2218 & 34.4 & 46.4 & 990 & 2218 & 34.4 & 46.4 & 0.00 & 0.02 & 0.02 & 0.03 \\
\hline Schneller & 4751 & 30 & 0.6 & 930 & 2018 & 17.3 & 82.6 & 930 & 2018 & 17.3 & 82.6 & 0.01 & 0.13 & 0.02 & 0.09 \\
\hline Morse & 24186 & 111 & 0.5 & 950 & 2138 & 46.4 & 79.0 & 950 & 2138 & 46.4 & 79.0 & 0.00 & 0.05 & 0.02 & 0.04 \\
\hline Kibalchich & 1752 & 7 & 0.4 & 970 & 2058 & 0.0 & 19.5 & 970 & 2058 & 0.0 & 19.5 & 0.02 & 0.02 & 0.02 & 0.02 \\
\hline Kulik L & 3787 & 15 & 0.4 & 910 & 2218 & 32.8 & 51.1 & 910 & 2218 & 32.8 & 51.1 & 0.00 & 0.03 & 0.02 & 0.03 \\
\hline Rowland M & 11512 & 36 & 0.3 & 930 & 2058 & 16.5 & 121.6 & 930 & 2058 & 16.5 & 121.6 & 0.02 & 0.09 & 0.02 & 0.06 \\
\hline Coriolis Y & 5488 & 16 & 0.3 & 990 & 2218 & 69.2 & 236.0 & 990 & 2218 & 69.2 & 236.0 & 0.00 & 0.04 & 0.02 & 0.02 \\
\hline Anderson F & 7180 & 16 & 0.2 & 1010 & 2258 & 14.6 & 35.7 & 1010 & 2258 & 14.6 & 35.7 & 0.01 & 0.02 & 0.02 & 0.03 \\
\hline Lebedinskiy & 3614 & 6 & 0.2 & 950 & 2138 & 0.0 & 54.5 & 950 & 2138 & 0.0 & 54.5 & 0.03 & 0.05 & 0.02 & 0.02 \\
\hline Freundlich & 14525 & 16 & 0.1 & 970 & 2138 & 76.4 & 29.2 & 970 & 2138 & 76.4 & 29.2 & 0.01 & 0.02 & 0.02 & 0.03 \\
\hline Daedalus W & 5837 & 6 & 0.1 & 970 & 2098 & 0.0 & 30.1 & 970 & 2098 & 0.0 & 30.1 & 0.03 & 0.05 & 0.02 & 0.04 \\
\hline Lodygin & 5418 & 4 & 0.1 & 950 & 2297 & 48.9 & 105.0 & 950 & 2297 & 48.9 & 105.0 & 0.01 & 0.02 & 0.02 & 0.02 \\
\hline Coriolis & 7693 & 2 & 0.0 & 1010 & 2098 & 0.0 & 0.0 & 1010 & 2098 & 0.0 & 0.0 & 0.01 & 0.01 & 0.02 & 0.02 \\
\hline Amici $\mathrm{T}$ & 8515 & 2 & 0.0 & 910 & 2258 & 0.0 & 0.0 & 910 & 2258 & 0.0 & 0.0 & 0.01 & 0.01 & 0.02 & 0.02 \\
\hline Dante & 4965 & 1 & 0.0 & 1010 & 2297 & - & - & 1010 & 2297 & - & - & 0.01 & 0.01 & 0.02 & 0.02 \\
\hline Daedalus & 13748 & 2 & 0.0 & 950 & 1978 & 0.0 & 0.0 & 950 & 1978 & 0.0 & 0.0 & 0.05 & 0.05 & 0.03 & 0.03 \\
\hline Spencer Jones & 14559 & 2 & 0.0 & 950 & 2098 & 0.0 & 0.0 & 950 & 2098 & 0.0 & 0.0 & 0.03 & 0.03 & 0.02 & 0.02 \\
\hline Keeler & 48413 & 4 & 0.0 & 950 & 2258 & 0.0 & 23.1 & 950 & 2258 & 0.0 & 23.1 & 0.01 & 0.03 & 0.02 & 0.03 \\
\hline Amici U & 13851 & 0 & 0.0 & 0 & 0 & 0.0 & 0.0 & 0 & 0 & 0.0 & 0.0 & 0.00 & 0.00 & 0.00 & 0.00 \\
\hline Gadomski & 8332 & 0 & 0.0 & 0 & 0 & 0.0 & 0.0 & 0 & 0 & 0.0 & 0.0 & 0.00 & 0.00 & 0.00 & 0.00 \\
\hline Hayford & 1477 & 0 & 0.0 & 0 & 0 & 0.0 & 0.0 & 0 & 0 & 0.0 & 0.0 & 0.00 & 0.00 & 0.00 & 0.00 \\
\hline
\end{tabular}


Table 1 (continued).

\begin{tabular}{|c|c|c|c|c|c|c|c|c|c|c|c|c|c|c|c|}
\hline Crater & $\begin{array}{l}\mathrm{Nr} \text { pixels } \\
\text { total in } \mathrm{CP}\end{array}$ & $\begin{array}{l}\mathrm{Nr} \\
\text { pixels }\end{array}$ & $\begin{array}{l}\% \mathrm{CP} \\
\text { covered }\end{array}$ & $\begin{array}{l}\text { Median B1 } \\
\text { sup. } 2 \%\end{array}$ & $\begin{array}{l}\text { Median B2 } \\
\text { sup. } 2 \%\end{array}$ & $\begin{array}{l}\sigma B 1 \\
\text { sup. } 2 \%\end{array}$ & $\begin{array}{l}\sigma B 2 \\
\text { sup. } 2 \%\end{array}$ & $\begin{array}{l}\text { Median B1 } \\
200 \text { pix }\end{array}$ & $\begin{array}{l}\text { Median B2 } \\
200 \text { pix }\end{array}$ & $\begin{array}{l}\sigma B 1 \\
200 \text { pix }\end{array}$ & $\begin{array}{l}\sigma B 2 \\
200 \text { pix }\end{array}$ & $\begin{array}{l}\text { BD1 } \\
\min \end{array}$ & $\begin{array}{l}\text { BD1 } \\
\max \end{array}$ & $\begin{array}{l}\mathrm{BD} 2 \\
\min \end{array}$ & $\begin{array}{l}\text { BD2 } \\
\max \end{array}$ \\
\hline Krasovskiy & 2933 & 0 & 0.0 & 0 & 0 & 0.0 & 0.0 & 0 & 0 & 0.0 & 0.0 & 0.00 & 0.00 & 0.00 & 0.00 \\
\hline Krasovskiy L & 7619 & 0 & 0.0 & 0 & 0 & 0.0 & 0.0 & 0 & 0 & 0.0 & 0.0 & 0.00 & 0.00 & 0.00 & 0.00 \\
\hline Rowland & 20876 & 0 & 0.0 & 0 & 0 & 0.0 & 0.0 & 0 & 0 & 0.0 & 0.0 & 0.00 & 0.00 & 0.00 & 0.00 \\
\hline Spencer Jones W & 5078 & 0 & 0.0 & 0 & 0 & 0.0 & 0.0 & 0 & 0 & 0.0 & 0.0 & 0.00 & 0.00 & 0.00 & 0.00 \\
\hline Trumpler V & 4857 & 0 & 0.0 & 0 & 0 & 0.0 & 0.0 & 0 & 0 & 0.0 & 0.0 & 0.00 & 0.00 & 0.00 & 0.00 \\
\hline Valier & 10317 & 0 & 0.0 & 0 & 0 & 0.0 & 0.0 & 0 & 0 & 0.0 & 0.0 & 0.00 & 0.00 & 0.00 & 0.00 \\
\hline Virtanen & 7790 & 0 & 0.0 & 0 & 0 & 0.0 & 0.0 & 0 & 0 & 0.0 & 0.0 & 0.00 & 0.00 & 0.00 & 0.00 \\
\hline
\end{tabular}

\section{Results}

\subsection{Mineralogical detections}

This study's mineralogical detections are shown in Fig. 3a.

Fig. $3 \mathrm{~b}, \mathrm{c}$ and $\mathrm{d}$ show previous work on the lithology and mineralogy of central peak craters located in the FHT-a from Tompkins and Pieters (1999) (using Clementine ultraviolet-visible multispectral data), Lemelin et al. (2015) (using Kaguya multiband imager data), and Donaldson Hanna et al. (2014) (using $\mathrm{M}^{3}$ data from all optical periods). The mineralogical detections from all studies are in general agreement.

In the craters selected here (Fig. 3a), HCP, featureless spectra and plagioclase occurrences are detected. HCP is detected in the vast majority of studied craters ( 60 out of 75 craters). Featureless spectra are observed at all latitudes in the FHT-a (44 out of 75 craters), and some plagioclase occurrences are detected ( 7 out of 75 craters). LCP, olivine and spinel occurrences were also searched for. Their presence on the surface cannot be ruled out, but their spectral signature was absent from the orbital data used on the selection of studied craters - they were not observed in this study.
HCP spectra are observed in a wide range of $\mathrm{P}_{c m i}$ values (between 45.7 and $-1.5 \mathrm{~km}$, see Table A.3 in supplementary material). Featureless spectra are observed in craters spanning the whole range of $\mathrm{P}_{c m i}$ values (between 48.9 and $-1.5 \mathrm{~km}$ ). Plagioclase is only detected in craters having a positive $\mathrm{P}_{c m i}$ value (between 39.2 and $12.1 \mathrm{~km}$ ).

Featureless spectra occurrences span across all crater ages (ages taken from the LICD, Losiak et al. (2009), revised by Ohman at LPI), whereas plagioclase occurrences appear more concentrated in younger craters (Copernican to Eratosthenian in age). The plagioclase detections reported here are concentrated in the center of the FHT-a (5 out of 7 detections), and in its southern portion (2 out of 7 detections). Featureless occurrences span a wider range of latitude, from the South to the North of the FHT-a (Fig. 3a). The band 1 and 2 positions for all 60 craters where HCP was detected are shown in Table 1.

In the craters present in both Tompkins and Pieters (1999) and this study's selections, pyroxene was detected where Tompkins and Pieters (1999) detected pyroxene-compatible lithologies (anorthositic troctolite, anorthositic gabbronorite, anorthositic gabbro and gabbroicnoritic-troctilitic anorthosite containing less than $90 \%$ plagioclase).

Plagioclase or featureless spectra were detected in the craters where Lemelin et al. (2015) reported between 88 and 95\% plagioclase, and locations of the highest plagioclase contents from Lemelin et al. (2015) (Fig. 3c) are in agreement with the most anorthositic detections
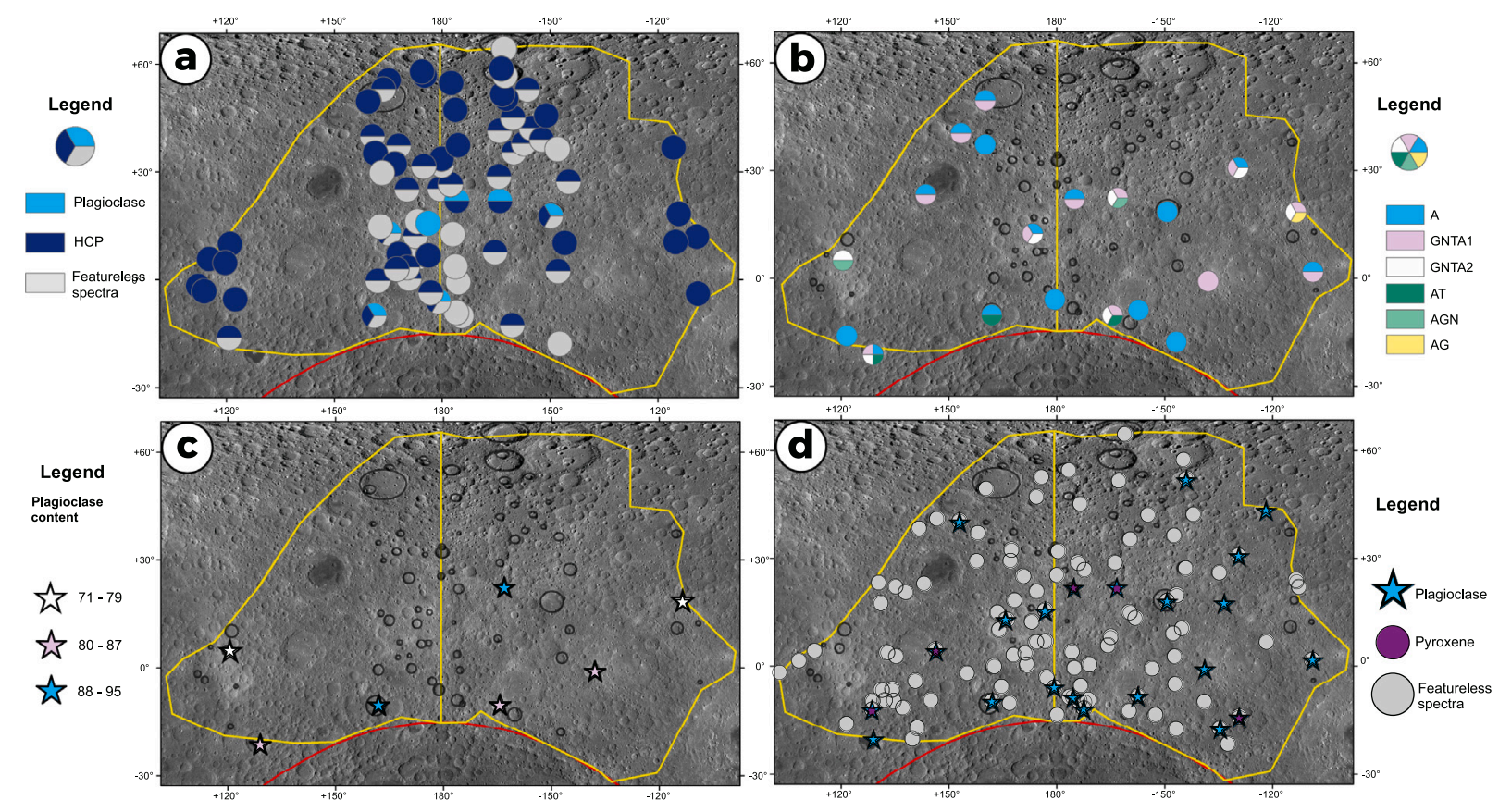

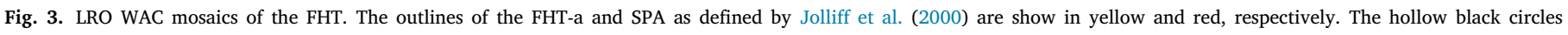

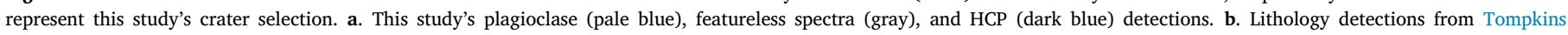

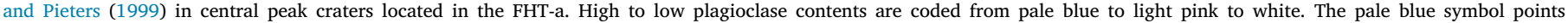

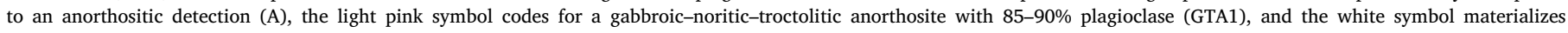

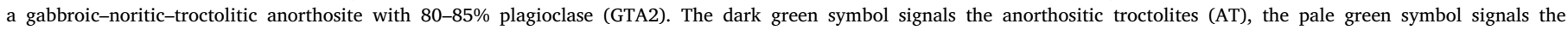

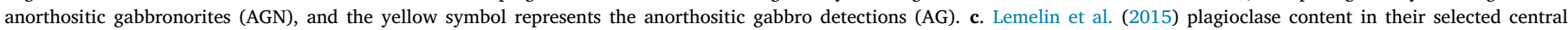

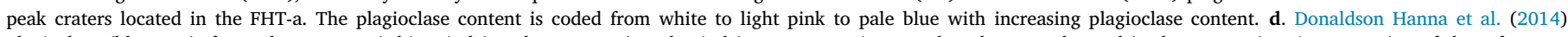

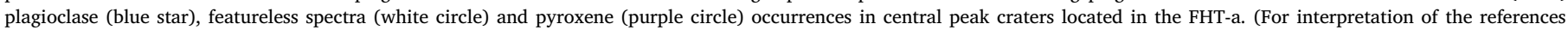
to color in this figure legend, the reader is referred to the web version of this article.) 
from Tompkins and Pieters (1999). There is also a good agreement between the anorthositic detections by Tompkins and Pieters (1999) and the plagioclase occurrences detected by Donaldson Hanna et al. (2014) (Fig. 3d). No plagioclase was detected in the craters where Lemelin et al. (2015) estimated less than 79\% plagioclase.

In craters that are part of both Donaldson Hanna et al. (2014) and this study's selections, pyroxene detections are consistent. In some cases, plagioclase occurrences were reported by Donaldson Hanna et al. (2014) in central peaks where we did not detect them, but the detections reported by Donaldson Hanna et al. (2014) were made on $\mathrm{M}^{3}$ data from the OP2C3 optical period. One interesting thing to note is that the optical period OP2C3 data was obtained with a colder detector than the optical period OP2C2 data used here.

\subsection{Pyroxene compositional variations}

As discussed in Section 2.2, we used a method similar to that described in the study by Moriarty et al. (2013), to evaluate the pyroxene compositional variations in these craters. The global median and the median of the 200 pixels with strongest band depth were calculated for three classes: spectra with band depth values between 2 and 5.5\% in a first class, spectra with band depth values between 5.5 and $7 \%$ in a second class, and spectra with band depth values larger than 7\% in a third class. These classes were defined in order to check if the composition of pyroxene remains the same with increasing band depth values. The results are presented in Table 2 . In general, the band depth values are homogeneous in the different band depth classes: in all cases, the band 2 position difference between the classes does not exceed 3 spectral channels (about $120 \mathrm{~nm}$ ). In all craters where more than $2 \%$ of the central peak has a pyroxene signature, the 200 pixels with strongest absorption band depth are located within a contiguous region. These observations suggest a homogeneous composition within a single central peak.

Fig. 4a shows the position of the band 2 center (median per central peak as outlined in the Methods section) as a function of the distance to the SPA basin center. The band 2 position spans between 2018 and $2337 \mathrm{~nm}$ in the whole investigated range (1200 to $3400 \mathrm{~km}$ from the SPA basin center), compatible with a HCP composition (e.g., Cloutis and Gaffey, 1991; Klima et al., 2011). Fig. 4b shows the position of the band 2 center as a function of the depth within the SPA basin ejecta blanket. The depth in the SPA basin ejecta was calculated by subtracting the depth of melting (depth of origin of the material emplaced in a central peak, Cintala and Grieve (1998)) to the ejecta thickness at the center of the considered crater (calculated with the equation (1) from McGetchin et al. (1973)). Positive values represent depths within the SPA ejecta, while negative values represent depths below the SPA ejecta, i.e., in the lunar crust.

No significant trend with depth within the SPA ejecta or distance to SPA appears in the band 2 positions (Fig. $4 \mathrm{a}, \mathrm{b}$ ).

\section{Discussion}

\subsection{Mineralogy}

The mineralogical detections presented in this study are generally in good agreement with results from previous remote sensing surveys. (Cheek et al., 2013) showed that pyroxene can spectrally dominate a rock composed of $<95 \%$ plagioclase, which is consistent with the lack of plagioclase detections in craters where Lemelin et al. (2015) estimated less than $79 \%$ plagioclase.

In some cases, Donaldson Hanna et al. (2014) reported plagioclase occurrences in central peaks where it was not detected in this study (even when using the spectral parameters developed for the detection of plagioclase, BD1250 and IBD1250). This can be explained by the fact that Donaldson Hanna et al. (2014) used $\mathrm{M}^{3}$ observations in all
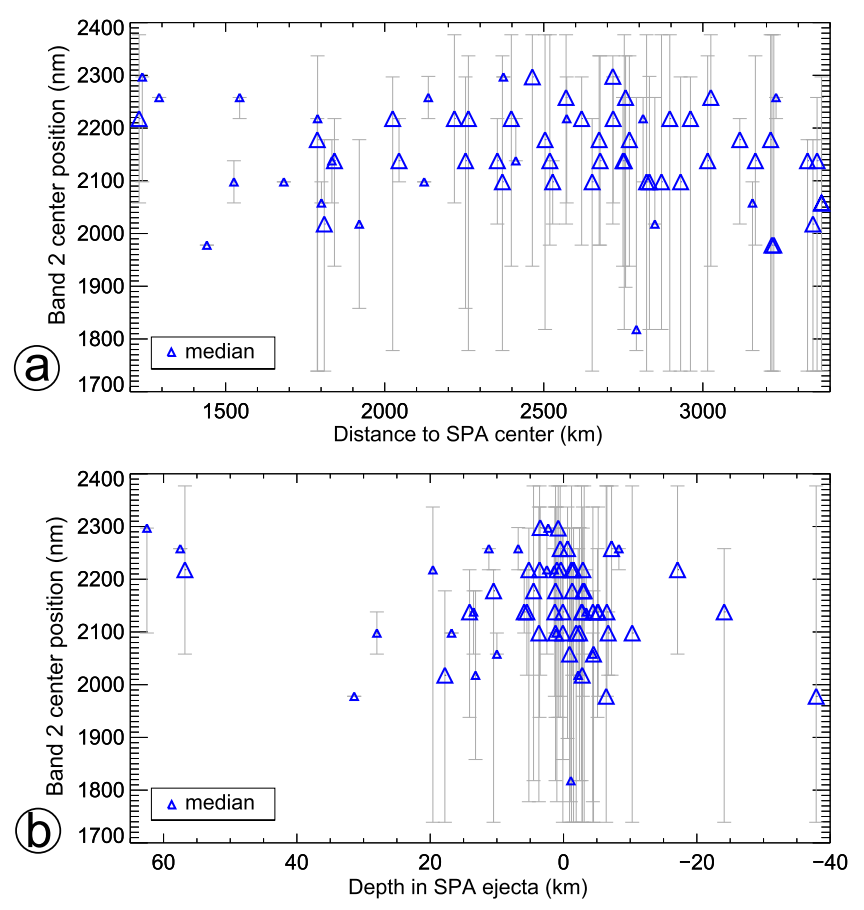

Fig. 4. a. Position of the median band 2 center as a function of the distance to the SPA basin center. Blue triangles represent the median of the 200 central peak pixels with strongest band depth that have both a band depth stronger than $2 \%$, and which band 2 center position fall between 1700 and $2400 \mathrm{~nm}$. When less than 200 pixels were represented in the central peak, the median of all pixels was calculated. Symbol size depend on the number of central peak pixels having a pyroxene signature. The symbol is small if there are fewer than 50 pixels; large if there are more than 50 pixels. Vertical error bars indicate the minimum and maximum band 2 center position. b. Position of the median band 2 center as a function of the depth in the SPA basin ejecta (calculated with Eq. (1)).

optical periods, whereas only optical period OP2C2 was considered in the present study.

The featureless spectra occurrences from Donaldson Hanna et al. (2014) and this study are generally in good agreement. In some craters (24 out of 33 craters in common), Donaldson Hanna et al. (2014) detected only featureless spectra, while pyroxene and/or featureless spectra were detected using our method.

Lucey (2002) studied featureless spectra and proposed that they formed from a space weathered plagioclase. A potential link between age of the crater and presence of featureless spectra was investigated in this study. However, the age of craters where featureless detections are observed in this study span a wide range of ages, from Pre-Nectarian ages to Copernican ages. Therefore, we cannot link their occurrence to terrain maturation. Plagioclase occurrences from this study are concentrated in younger craters (Copernican to Eratosthenian in age). Nonetheless, Donaldson Hanna et al. (2014) detected plagioclase both in young and old craters (the oldest is pre-Nectarian Mach crater). Consequently, no clear link between plagioclase, featureless spectra occurrences and crater age is observed.

In the craters selected for this study, plagioclase occurrences are concentrated in the center and South of the FHT-a, and featureless spectra detections are mainly concentrated in the center of the FHTa. HCP occurrences are dispersed throughout the whole FHT-a, and the periphery of FHT-a seems to be richer in HCP than its center. This could be explained by a mixing with the nearby PKT, mare or cryptomare material. The locations of the plagioclase and featureless spectra detections from Donaldson Hanna et al. (2014) however show that plagioclase and featureless spectra are widely dispersed throughout the FHT-a. 
Table 2

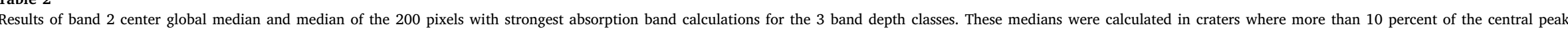

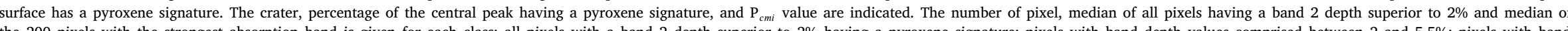

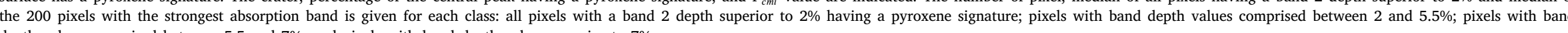
depth values comprised between 5.5 and 7\%; and pixels with band depth values superior to 7\%.

\begin{tabular}{|c|c|c|c|c|c|c|c|c|c|c|c|c|c|c|}
\hline \multirow[t]{2}{*}{ Name } & \multirow[t]{2}{*}{ Percent_CP } & \multirow[t]{2}{*}{$\mathrm{P}_{c m i}$ value } & \multicolumn{3}{|c|}{ Band 2 depth superior to $2 \%$ class } & \multicolumn{3}{|c|}{ Band 2 depth from 2 to $5.5 \%$ class } & \multicolumn{3}{|c|}{ Band 2 depth from 5.5 to $7 \%$ class } & \multicolumn{3}{|c|}{ Band 2 depth superior to $7 \%$ class } \\
\hline & & & $\begin{array}{l}\mathrm{Nr} \\
\text { pixels }\end{array}$ & $\begin{array}{l}\text { Median } \\
\text { sup. } 2 \%\end{array}$ & $\begin{array}{l}\text { First } 200 \\
\text { median }\end{array}$ & $\begin{array}{l}\mathrm{Nr} \\
\text { pixels }\end{array}$ & $\begin{array}{l}\text { Median } \\
\text { sup. } 2 \%\end{array}$ & $\begin{array}{l}\text { First } 200 \\
\text { median }\end{array}$ & $\begin{array}{l}\mathrm{Nr} \\
\text { pixels }\end{array}$ & $\begin{array}{l}\text { Median } \\
\text { sup. } 2 \%\end{array}$ & $\begin{array}{l}\text { First } 200 \\
\text { median }\end{array}$ & $\begin{array}{l}\mathrm{Nr} \\
\text { pixels }\end{array}$ & $\begin{array}{l}\text { Median } \\
\text { sup. } 2 \%\end{array}$ & $\begin{array}{l}\text { First } 200 \\
\text { median }\end{array}$ \\
\hline King & 98.1 & 28.2 & 24693 & 2138 & 2138 & 18103 & 2138 & 2138 & 4109 & 2098 & 2138 & 2481 & 2098 & 2098 \\
\hline Necho & 95.8 & 39.6 & 9666 & 2098 & 2178 & 8692 & 2098 & 2178 & 815 & 2098 & 2098 & 159 & 2098 & 2098 \\
\hline $\mathrm{Ohm}$ & 91.5 & 32.9 & 9877 & 2218 & 2218 & 7907 & 2218 & 2218 & 1258 & 2178 & 2178 & 712 & 2178 & 2178 \\
\hline Moore F & 90.5 & 45.3 & 2510 & 2258 & 2298 & 2409 & 2258 & 2298 & 93 & 2178 & 2178 & 8 & 2178 & 2178 \\
\hline Montgolfier Y & 86.3 & 40.0 & 63 & 2178 & 2178 & 63 & 2178 & 2178 & 0 & - & - & 0 & - & - \\
\hline Larmor Z & 77.4 & 38.9 & 2370 & 2178 & 2218 & 2322 & 2178 & 2218 & 46 & 2138 & 2138 & 2 & 2138 & 2138 \\
\hline Tsinger Y & 70.3 & 35.2 & 1293 & 2098 & 2058 & 1119 & 2098 & 2058 & 45 & 2138 & 2138 & 129 & 2098 & 2098 \\
\hline d'Alembert Z & 67.2 & 35.7 & 844 & 2058 & 2018 & 649 & 2058 & 2018 & 127 & 2058 & 2058 & 68 & 2058 & 2058 \\
\hline Tsinger & 36.5 & 34.1 & 84 & 2138 & 2138 & 84 & 2138 & 2138 & 0 & - & - & 0 & - & - \\
\hline Delporte & 30.2 & 35.9 & 256 & 2098 & 2098 & 256 & 2098 & 2098 & 0 & - & - & 0 & - & - \\
\hline dAlembert & 28.1 & -1.5 & 6076 & 2018 & 1978 & 6066 & 2018 & 1978 & 6 & 2018 & 2018 & 4 & 2058 & 2058 \\
\hline Rowland $\mathrm{J}$ & 21.0 & 37.4 & 4376 & 2178 & 2178 & 4127 & 2178 & 2178 & 187 & 2178 & 2178 & 62 & 2138 & 2138 \\
\hline Golovin & 17.0 & 40.0 & 437 & 2098 & 2098 & 437 & 2098 & 2098 & 0 & - & - & 0 & - & - \\
\hline Coriolis W & 15.6 & 34.3 & 1077 & 2018 & 2018 & 1075 & 2018 & 2018 & 2 & 2018 & 2018 & 0 & - & - \\
\hline Slipher & 15.0 & 32.0 & 2058 & 2058 & 1978 & 2058 & 2058 & 1978 & 0 & - & - & 0 & - & - \\
\hline Woltjer & 15.0 & 38.8 & 961 & 2178 & 2218 & 961 & 2178 & 2218 & 0 & - & - & 0 & - & - \\
\hline Jackson & 14.1 & 39.2 & 2589 & 2138 & 2218 & 2370 & 2178 & 2218 & 128 & 2018 & 2018 & 91 & 2018 & 2018 \\
\hline Stearns & 12.6 & 37.7 & 811 & 2138 & 2178 & 809 & 2138 & 2178 & 2 & 2138 & 2138 & 0 & - & - \\
\hline Kulik J & 12.6 & 38.8 & 897 & 2218 & 2218 & 897 & 2218 & 2218 & 0 & - & - & 0 & - & - \\
\hline Evershed C & 10.6 & 41.9 & 744 & 2258 & 2258 & 744 & 2258 & 2258 & 0 & - & - & 0 & - & - \\
\hline
\end{tabular}




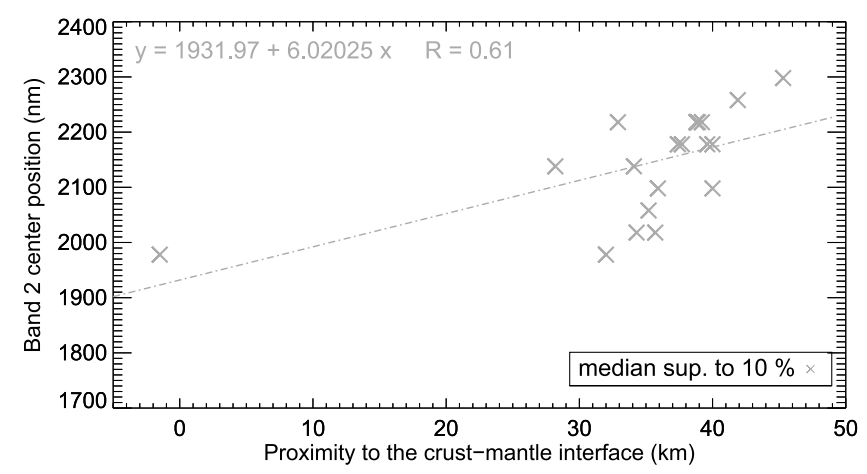

Fig. 5. Position of the band 2 center as a function of the $\mathrm{P}_{c m i}$ value for all craters in which more than 10 percent of the central peak surface has a pyroxene signature (gray crosses). The linear regression is shown as a dotted line.

\subsection{Central peak pyroxene compositional variation}

The mineralogical detections presented here have spectra with relatively shallow band depths: the strongest band 2 depth of all surveyed spectra in the craters selection was equal to $20 \%$. When looking at band depth classes, it is worth noting that the strongest classes are generally located on topographic highs, where rocks outcrop. In the case of King, Moore $\mathrm{F}$ and Tsinger $\mathrm{Y}$ craters, the position of the band 2 center shifts towards longer wavelength with decreasing band depth. Moriarty et al. (2013) interpreted this to be caused by the development of soil post-impact, rather than significant changes in composition. This is supported by the fact that the difference between the minimum and maximum band 2 position as a function of band depth does not exceed 3 spectral channels (about $120 \mathrm{~nm}$ ) in all craters where HCP was identified, suggesting that pyroxene composition does not vary significantly within individual central peaks. Thus, the pyroxene composition of the surveyed central peak is fairly homogeneous within each central peak.

Hawke et al. (2003) first introduced the idea of a mixed layer, formed during the LMO crystallization, and resulting from impact events depositing pyroxene-bearing, mafic material on top of the pure anorthositic crust formed by flotation. They also proposed that the SPA impact event deposited ejecta material on top of the crust, in thick pile close to SPA, which should be thinning as the distance to SPA increases. Moriarty and Pieters (2018) recently described four compositionally different units in the SPA basin, organized radially. The SPA center has a HCP signature. It is surrounded by a Mg-pyroxene annulus, then a heterogeneous annulus where more anorthositic-rich material is observed, and finally a highly feldspathic, mafic-free SPA exterior.

We attempted to identify if a significant SPA basin ejecta signature exists, and if it changes with distance from the SPA basin center. We observe no link between the position of the band 2 center and the distance to SPA, or the depth within the SPA ejecta (Fig. 4). This hints that the material ejected by the SPA impact event was probably reworked by the numerous subsequent impact events, and the material ejected by the SPA-forming event is no longer discernible from the FHTa material. An alternative explanation would be that the mineralogical composition of the SPA ejecta material is very similar to that of the FHT-a crust.

Several studies pointed at the existence of a global anorthositic layer, buried under a shallow (3 to $10 \mathrm{~km}$ thick) layer of more pyroxene-rich material (Hawke et al., 2003; Ohtake et al., 2009; Yamamoto et al., 2012a; Donaldson Hanna et al., 2014). The results from Tompkins and Pieters (1999) and Lemelin et al. (2015) point at a plagioclase-rich FHT-a crust. Only seven plagioclase occurrences were detected in this study. However, Lucey (2002) discussed that space weathering of plagioclase can cause featureless spectra, and the study of shocked plagioclase reflectance spectra showed that shock pressures can trigger the weakening or disappearance of plagioclase absorption band (Adams and Hörz, 1979; Bruckenthal and Pieters, 1984). The numerous featureless spectra occurrences reported here could therefore have formed from space weathered or shocked anorthositic material.

The plagioclase detections reported here are too scarce to draw any conclusions on the evolution of the plagioclase abundance with depth, so we are unable to confirm the proposed decrease in plagioclase abundance with increasing depth in the crust (Spudis and Davis, 1986; Tompkins and Pieters, 1999). However, the observation of plagioclase over a wide range of depth in the FHT-a crust is consistent with the existence of a thick anorthositic crust.

Craters where plagioclase and featureless spectra are detected do not cluster in a specific $\mathrm{P}_{c m i}$ values range, which implies the existence of a thick plagioclase-rich, anorthositic crust. The anorthosite crust is estimated to be $27 \mathrm{~km}$ thick if only craters where plagioclase is detected are taken into account; $50 \mathrm{~km}$ thick if both plagioclase and featureless spectra are considered. Ohtake et al. (2009), Yamamoto et al. (2012a) and Donaldson Hanna et al. (2014), respectively speculate the existence of a $27 \mathrm{~km}, 50 \mathrm{~km}$ and at least $30 \mathrm{~km}$ thick, discrete PAN-rich layer. The numerous HCP detections presented in this study at all investigated crustal depths are not in agreement with the existence of a discrete PAN-rich layer, but do not negate the existence of a thick (27 to $50 \mathrm{~km}$ ) plagioclase-rich, anorthositic crust. The numerous HCP detections in the FHT-a crust at all crustal depths support the presence of a thick anorthositic crust that is mingled with the mixed layer introduced by Hawke et al. (2003), where pyroxene-bearing material is mixed with anorthositic material through impact events. Alternatively, this mixing between plagioclase and pyroxene material could also be inherited from the LMO crystallization if pockets of residual mafic liquids were trapped between plagioclase-rich cumulates.

\subsection{Link between pyroxene composition and crustal depth}

Fig. 5 shows that a weak positive correlation between the position of the band 2 center and the proximity to the crust-mantle interface was observed. A weak linear regression suggests that the position of the band 2 band center shifts towards shorter wavelength with increasing depth as the distance to the crust-mantle interface decreases. Craters tapping upper crustal material seem to have a pyroxene signature that is more calcic than craters tapping material originating from closer to the crust-mantle interface. The change in pyroxene calcium content with depth is consistent with the results from Martinot et al. (2018b), who observed that the pyroxene signatures changes from HCP towards LCP at the crust-mantle interface on the basis of the analysis of 36 craters spreading the entire FHT (anorthositic and outer part as described by Jolliff et al. (2000)), and with the conclusions from Melosh et al. (2017), who proposed that the lunar upper mantle is LCP-rich.

It is worth insisting that pyroxene is spectrally dominant over plagioclase: Cheek and Pieters (2014) showed that as little as 2 vol.\% of pyroxene in a plagioclase-rich rock could hide a potential plagioclase signature. Therefore, the detection of pyroxene does not preclude the presence of plagioclase in a rock. Consequently, the detection of HCP in the FHT-a means that the mafic component of the FHT-a is spectrally dominated by HCP, but does not exclude that the rock petrologically fits the definition of an anorthosite.

Finally, to further analyze the compositional variations in pyroxenes detected in this study, we incorporate band 1 position analyses. The pyroxene compositions obtained from the pyroxene composition analysis in the central peaks was compared with the positions of the band 1 and 2 centers obtained by Adams (1974)'s study of orthopyroxene and clinopyroxene (Fig. 6). Fig. 6a presents Adams (1974)'s study of orthopyroxene and clinopyroxene band 1 and 2 centers with all studied impact craters where pyroxene was detected (60 out of 75 ). Fig. $6 \mathrm{~b}$ show the band 1 and 2 centers of the selected craters where more than $10 \%$ of the central peak has a pyroxene signature compared to the pyroxene selection from Adams (1974). Both panels also display the 


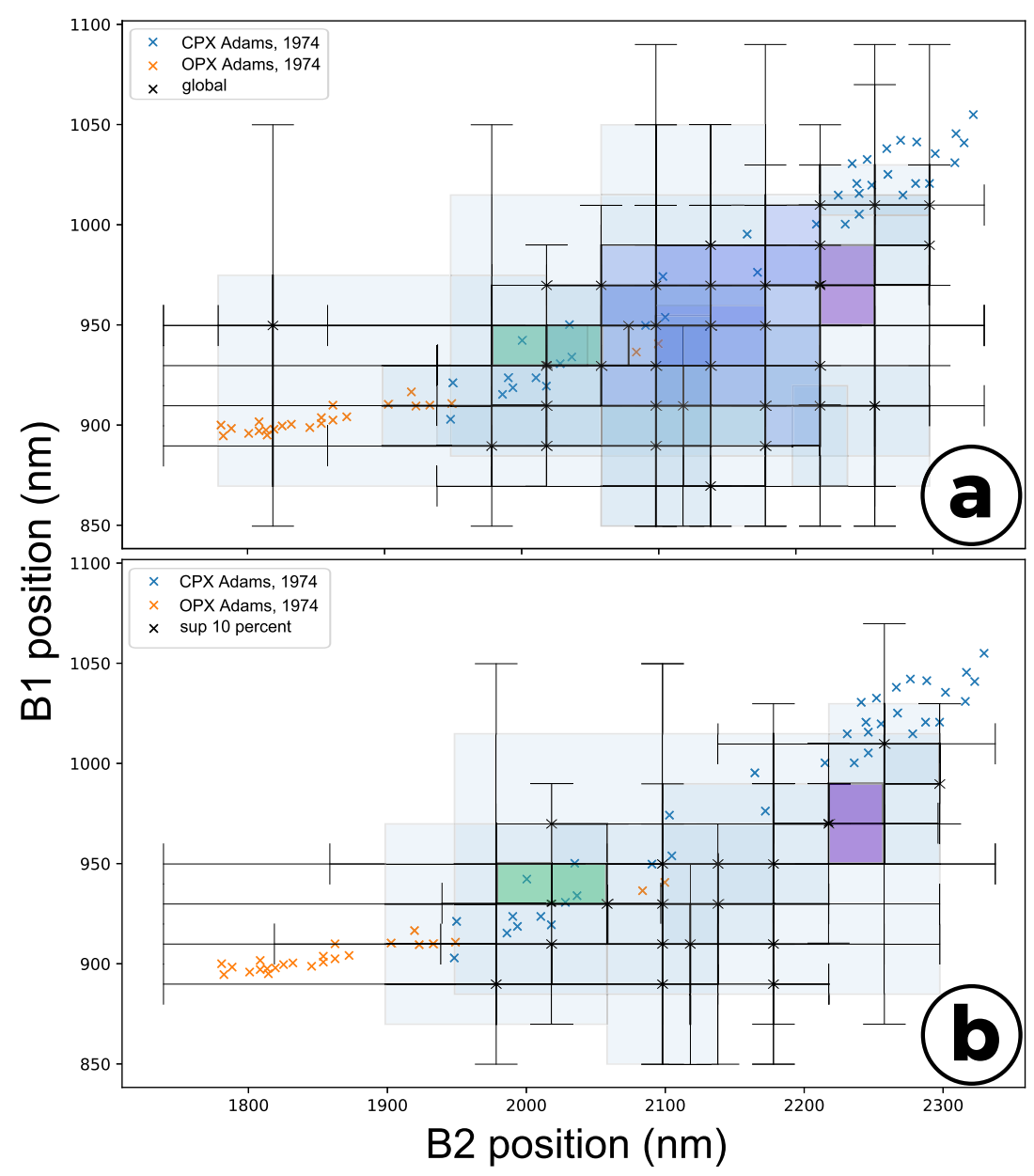

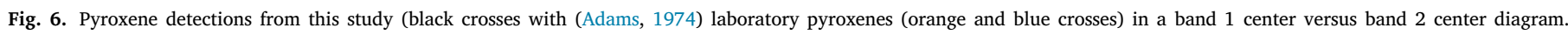

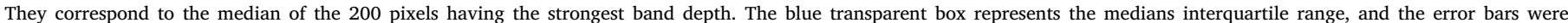

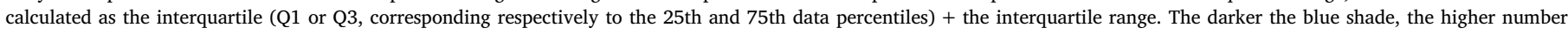

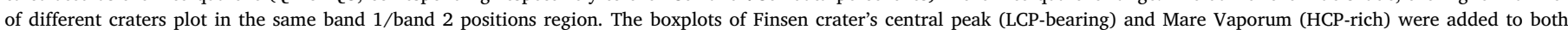

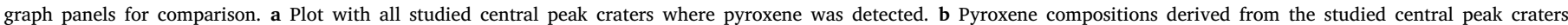

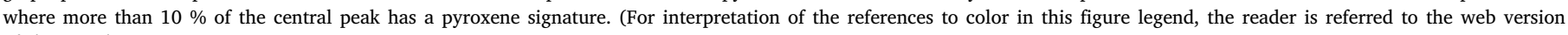
of this article.)

band 1/band 2 center ranges for Finsen crater where LCP was described in previous studies using $\mathrm{M}^{3}$ (Moriarty et al., 2013), and Mare Vaporum where HCP is found using the algorithm run for this study.

Some central peaks have pyroxene compositions with higher or lower calcium contents than Finsen crater and Mare Vaporum, but the majority of pyroxene compositions plots between Finsen crater and Mare Vaporum (the blue hue is more intense between Finsen crater and Mare Vaporum band 1/band 2 absorption band ranges).

The compositions of pyroxene observed in the studied central peaks are generally consistent with clinopyroxene (or HCP), and a small number of pyroxene compositions is compatible with orthopyroxene (or LCP), within error bars. This is consistent with the fact that the pyroxene calcium content changes with depth. The band 2 center of studied craters stretches until $2340 \mathrm{~nm}$, so the pyroxenes observed in this study are probably less calcic than the calcic endmember studied in Adams (1974). However, Moriarty and Pieters (2016) pointed out that single pyroxene grains can have important compositional variations (caused by zonation or exsolution for instance). It is therefore important to be cautious when comparing remote sensing spectra (which are averaged over a $280 \times 280 \mathrm{~m}$ pixel) to laboratory spectra of pure minerals.

\section{Conclusions}

The analysis of 75 impact craters' central peaks with spectroscopic data showed that HCP and featureless spectra are widely detected in the FHT-a. Limited plagioclase detections are reported here and are consistent with the existence of an anorthositic crust at least $27 \mathrm{~km}$ thick, which is probably mixed with pyroxene-bearing material emplaced during the LMO crystallization through impact events (Hawke et al., 2003).

Data hint at a pyroxene compositional change with depth. The composition of pyroxene is less calcic closer to the crust-mantle interface (i.e., with increasing depth). This result is compatible with the conclusions from Martinot et al. (2018b), who proposed that there is a transition from HCP to LCP around the crust-mantle interface. A transition from HCP to LCP at the crust-mantle interface is also consistent with the conclusions from Melosh et al. (2017), who proposed that the upper mantle is LCP-rich.

This study was limited to craters covered by $\mathrm{M}^{3}$ data from the optical period OP2C2, to allow cross-comparisons between the mineralogical detections. It would be helpful to add craters tapping material closer to the crust-mantle interface in order to assess the validity of this trend. The detection of pyroxene with low-calcium composition in craters tapping material originating from close to the crust-mantle interface would confirm the trend, whereas the detection of pyroxene with high-calcium composition would invalidate the trend. In the latter case, perhaps pyroxene compositions reflect the widespread emplacements of plutonic intrusions in the crust (e.g., Head and Wilson, 1992). 
At the time of the SPA formation, the ejecta from the SPA basin probably overprinted the FHT-a material (and the lunar surface more broadly). Yet, no significant SPA signature was detected, and no link between the position of the band 2 center and the distance to SPA or the depth in the SPA ejecta was observed despite using two different models for calculating the SPA ejecta thickness. This suggests that the material ejected by the SPA-forming event was reworked by subsequent impact craters and mixed with the FHT-a material, or that the ejected crust from the SPA impact event formation and the FHT-a crust were petrologically similar.

\section{Acknowledgments}

The authors would like to thank K. Donaldson-Hanna for kindly sharing her data, J.-F. Blanchette-Guertin for helping with the proximity calculations, L. Mandon for sharing useful data, F. Millet for helping with Python coding, and C. Brustel for helpful discussions. The authors are grateful for insightful comments from the reviewer and editor that greatly helped improve the paper. This work was supported by a Netherlands Organization for Scientific Research (NWO) Vici grant and a User Support Space Research grant from the Netherlands Space Office (NSO) to W.v.W. J.F. is supported by a CNES APR LIS-Luna funding and a CNRS Momentum grant. This is CRPG contribution number 2717. C.Q.N. is supported by European Research Council through the FP7/2007-2013/ERC grant agreement 280168. $\mathrm{M}^{3}$, LRO LOLA digital elevation model and LRO WAC data can be accessed in the PDS Geoscience Node, Lunar Orbital Data Explorer (http://ode.rsl.wustl. edu/). The GRAIL crustal thickness models archive is hosted at https: //figshare.com/articles/GRAIL_Crustal_Thickness_Archive/6915155/1. The Lunar Impact Crater Database is available at https://www.lpi.usra. edu/lunar/surface/Lunar_Impact_Crater_Database_v08Sep2015.xls.

\section{Appendix A. Supplementary data}

Supplementary material related to this article can be found online at https://doi.org/10.1016/j.icarus.2020.113747.

\section{References}

Adams, J.B., 1974. Visible and near-infrared diffuse reflectance spectra of pyroxenes as applied to remote sensing of solid objects in the solar system. J. Geophys. Res. 79, 4829. http://dx.doi.org/10.1029/JB079i032p04829.

Adams, J.B., Goullaud, L.H., 1978. Plagioclase feldspars: visible and near infrared diffuse reflectance spectra as applied to remote sensing. In: Proc. Lunar Planet. Sci. Conf., pp. 1205-1207.

Adams, J.B., Hörz, R.V., 1979. Effects of shock-loading on the reflectance spectra of plagioclase, pyroxene, and glass. In: Proceedings of the 10th Lunar and Planetary Science Conference, pp. 5-7.

Arai, T., Takeda, H., Yamaguchi, A., Ohtake, M., 2008. A new model of lunar crust: asymmetry in crustal composition and evolution. Earth Planets Space 60, 433-444.

Besse, S., Sunshine, J., Staid, M., Boardman, J., Pieters, C., Guasqui, P., Malaret, E., McLaughlin, S., Yokota, Y., Li, J.Y., 2013. A visible and near-infrared photometric correction for moon mineralogy mapper $\left(\mathrm{m}^{3}\right)$. Icarus 222, 229-242. http://dx.doi. org/10.1016/j.icarus.2012.10.036.

Bills, B.G., Ferrari, A.J., 1977. A lunar density model consistent with topographic, gravitational, librational, and seismic data. J. Geophys. Res. 82, 1306-1314.

Boardman, J.W., Pieters, C.M., Green, R.O., Lundeen, S.R., Varanasi, P., Nettles, J., Petro, N.E., Isaacson, P., Besse, S., Taylor, L.A., 2011. Measuring moonlight: An overview of the spatial properties, lunar coverage, selenolocation, and related level $1 \mathrm{~b}$ products of the moon mineralogy mapper. J. Geophys. Res. E: Planets 116, 1-15. http://dx.doi.org/10.1029/2010JE003730.

Borg, L.E., Gaffney, A.M., Shearer, C.K., 2015. A review of lunar chronology revealing a preponderance of 4.34-4.37 Ga ages. Meteorit. Planet. Sci. 50, 715-732. http: //dx.doi.org/10.1111/maps.12373.

Borg, L., Norman, M., Nyquist, L., Bogard, D., Snyder, G., Taylor, L., Lindstrom, M., 1999. Isotopic studies of ferroan anorthosite 62236: A young lunar crustal rock from a light rare-earth-element-depleted source. Geochim. Cosmochim. Acta 63, 2679-2691. http://dx.doi.org/10.1016/S0016-7037(99)00130-1.

Bruckenthal, E.A., Pieters, C.M., 1984. Spectral Effects of Natural Shock on Plagioclase Felsdpar. Lunar and Planetary Institute, Cambridge, pp. 96-97.
Cahill, J.T.S., Lucey, P.G., Wieczorek, M.A., 2009. Compositional variations of the lunar crust: Results from radiative transfer modeling of central peak spectra. J. Geophys. Res. E: Planets 114, 1-17. http://dx.doi.org/10.1029/2008JE003282.

Charlier, B., Grove, T.L., Namur, O., Holtz, F., 2018. Crystallization of the lunar magma ocean and the primordial mantle-crust differentiation of the moon. Geochim. Cosmochim. Acta 234, 50-69. http://dx.doi.org/10.1016/j.gca.2018.05.006.

Cheek, L.C., Donaldson Hanna, K.L., Pieters, C.M., Head, J.W., Whitten, J.L., 2013. The distribution and purity of anorthosite across the orientale basin: New perspectives from moon mineralogy mapper data. J. Geophys. Res.: Planets 118, 1805-1820. http://dx.doi.org/10.1002/jgre.20126.

Cheek, L.C., Pieters, C.M., 2014. Reflectance spectroscopy of plagioclase-dominated mineral mixtures: Implications for characterizing lunar anorthosites remotely. Amer. Mineral. 99, 1871-1892. http://dx.doi.org/10.2138/am-2014-4785.

Cintala, M.J., Grieve, R.A.F., 1998. Scaling impact melting and crater dimensions: Implications for the lunar cratering record. Meteorit. Planet. Sci. 33, 889-912. http://dx.doi.org/10.1111/j.1945-5100.1998.tb01695.x.

Clark, R.N., Pieters, C.M., Green, R.O., Boardman, J.W., Petro, N.E., 2011. Thermal removal from near-infrared imaging spectroscopy data of the moon. http://dx.doi. org/10.1029/2010JE003751.

Cloutis, E.A., Gaffey, M.J., 1991. Pyroxene spectroscopy revisited: Spectralcompositional correlations and relations to geothermometry. J. Geophys. Res. 96, 22809-22826.

Donaldson Hanna, L.C., Pieters, C.M., Mustard, J.F., Greenhagen, B.T., Thomas, I.R., Bowles, N.E., 2014. Global assessment of pure crystalline plagioclase across the moon and implications for the evolution of the primary crust. J. Geophys. Res.: Planets 119, 1516-1545. http://dx.doi.org/10.1002/2013JE004476.

Flahaut, J., Blanchette-Guertin, J.F., Jilly, C., Sharma, P., Souchon, A., Van Westrenen, W., Kring, D.A., 2012. Identification and characterization of science-rich landing sites for lunar lander missions using integrated remote sensing observations. Adv. Space Res. 50, 1647-1665. http://dx.doi.org/10.1016/j.asr.2012.05.020.

Green, R.O., Pieters, C., Mouroulis, P., Eastwood, M., Boardman, J., Glavich, T., Isaacson, P., Annadurai, M., Besse, S., Barr, D., Buratti, B., Cate, D., Chatterjee, A., Clark, R., Cheek, L., Combe, J., Dhingra, D., Essandoh, V., Geier, S., Goswami, J.N., Green, R., Haemmerle, V., Head, J., Hovland, L., Hyman, S., Klima, R., Koch, T., Kramer, G., Kumar, A.S.K., Lee, K., Lundeen, S., Malaret, E., McCord, T., McLaughlin, S., Mustard, J., Nettles, J., Petro, N.E., Plourde, K., Racho, C., Rodriquez, J., Runyon, C., Sellar, G., Smith, C., Sobel, H., Staid, M.I., Sunshine, J.M., Taylor, L., Thaisen, K., Tompkins, S., Tseng, H., Vane, G., Varanasi, P., White, M., Wilson, D., 2011. The moon mineralogy mapper $\left(\mathrm{m}^{3}\right)$ imaging spectrometer for lunar science: Instrument description, calibration, on-orbit measurements, science data calibration and on-orbit validation. J. Geophy. Res. E: Planets 116, 1-31. http://dx.doi.org/ 10.1029/2011JE003797.

Gross, J., Treiman, A.H., Mercer, C.N., 2014. Lunar feldspathic meteorites: Constraints on the geology of the lunar highlands, and the origin of the lunar crust. Earth Planet. Sci. Lett. 388, 318-328. http://dx.doi.org/10.1016/j.epsl.2013.12.006.

Hawke, B.R., Peterson, C.A., Blewett, D.T., Bussey, D.B.J., Lucey, P.G., Taylor, G.J., Spudis, P.D., 2003. Distribution and modes of occurrence of lunar anorthosite. J. Geophys. Res. 108, 1-16. http://dx.doi.org/10.1029/2002JE001890.

Head, J.W.I., Wilson, L., 1992. Lunar mare volcanism - stratigraphy, eruption conditions, and the evolution of secondary crusts. Geochim. Cosmochim. Acta 56, 2155-2175. http://dx.doi.org/10.1016/0016-7037(92)90183-J.

Housen, K.R., Schmidt, R.M., Holsapple, K.A., 1983. Crater ejecta scaling laws: fundamental forms based on dimensional analysis. J. Geophys. Res. 88, 2485-2499. http://dx.doi.org/10.1029/JB088iB03p02485.

Jaumann, R., Hiesinger, H., Anand, M., Crawford, I.A., Wagner, R., Sohl, F., Jolliff, B.L., Scholten, F., Knapmeyer, M., Hoffmann, H., Hussmann, H., Grott, M., Hempel, S., Köhler, K., Schmitz, N., Carpenter, J., Wieczorek, M.A., Spohn, T., Robinson, M.S., Oberst, J., 2012. Geology, geochemistry, and geophysics of the moon: Status of current understanding. Planet. Space Sci. 74, 15-41. http://dx.doi.org/10.1016/j. pss.2012.08.019.

Jolliff, B.L., Gillis, J.J., Haskin, L.A., Korotev, R.L., Wieczorek, M.A., 2000. Major lunar crustal terranes: Surface expressions and crust-mantle origins. J. Geophys. Res. 105, 4197. http://dx.doi.org/10.1029/1999JE001103.

Kaula, W.M., 1979. Thermal evolution of earth and moon growing by planetesimal impacts. J. Geophys. Res. 84, 999-1008. http://dx.doi.org/10.1029/ JB084iB03p00999.

Klima, R.L., Pieters, C.M., Isaacson, P.J., Head, J.W., Petro, N.E., Staid, M., Sunshine, J.M., Taylor, L.A., 2011. Spectroscopic evidence of mg-rich low-Ca pyroxenes on the nearside of the moon. In: Lunar Planetary Science Conference. p. 42. http://dx.doi.org/10.1029/2006JE002868.

Laneuville, M., Taylor, J., Wieczorek, M.A., 2018. Distribution of radioactive heat sources and thermal history of the moon. J. Geophys. Res.: Planets http://dx.doi. org/10.1029/2018JE005742.

Lawrence, D.J., Feldman, W.C., Barraclough, B.L., Binder, A.B., Elphic, R.C., Maurice, S., Thomsen, D.R., 1998. Global elemental maps of the moon: The lunar prospector gamma-ray spectrometer. Science 281, 1484-1489.

Lemelin, M., Lucey, P.G., Song, E., Taylor, G.J., 2015. Lunar central peak mineralogy and iron content using the kaguya multiband imager: Reassessment of the compositional structure of the lunar crust. J. Geophys. Res.: Planets 120, 869-887. http://dx.doi.org/10.1002/2014JE004778. 
Lin, Y., Hui, H., Xia, X., Shang, S., van Westrenen, W., 2020. Experimental constraints on the solidification of a hydrous lunar magma ocean. Meteorit. Planet. Sci. 55, 207-230. http://dx.doi.org/10.1111/maps.13425.

Lin, Y., Tronche, E.J., Steenstra, E.S., van Westrenen, W., 2017a. Evidence for an early wet moon from experimental crystallization of the lunar magma ocean. Nat. Geosci. 1, 1-6. http://dx.doi.org/10.1038/ngeo2845.

Lin, Y., Tronche, E.J., Steenstra, E.S., van Westrenen, W., 2017b. Experimental constraints on the solidification of a nominally dry lunar magma ocean. Earth Planet. Sci. Lett. 471, 104-116. http://dx.doi.org/10.1016/j.epsl.2017.04.045.

Losiak, A., Wilhelms, D.E., Byrne, C.J., Thaisen, K., Weider, S.Z., Kohout, T., O'Sullivan, K., Kring, D.A., 2009. A new lunar impact crater database. In: Lunar and Planetary Science Conference.

Lucey, P.G., 2002. Radiative transfer model constraints on the shock state of remotely sensed lunar anorthosites. Geophys. Res. Lett. 29, 1-3. http://dx.doi.org/10.1029/ 2001GL014655.

Lucey, P.G., Cahill, J., 2006. Magnesian rock types in the lunar highlands: remote sensing using data from Lunar Prospector and Clementine. In: Lunar and Planetary Institute Science Conference.

Martinot, M., Besse, S., Flahaut, J., Quantin-Nataf, C., Lozac'h, L., van Westrenen, W., 2018a. Mineralogical diversity and geology of Humboldt crater derived using Moon Mineralogy Mapper data. J. Geophys. Res.: Planets (123), http://dx.doi.org/10. 1002/2017JE005435.

Martinot, M., Flahaut, J., Besse, S., Quantin-Nataf, C., van Westrenen, W., 2018b. Compositional variations in the vicinity of the lunar crust-mantle interface from Moon Mineralogy Mapper data. J. Geophys. Res.: Planets (123), http://dx.doi.org/ 10.1029/2018JE005744.

McGetchin, T.R., Settle, M., Head, J.W., 1973. Radial thickness variation in impact crater ejecta: Implications for lunar basin deposits. Earth Planet. Sci. Lett. 20, 226-236.

Melosh, H.J., 2011. Planetary surface processes. http://dx.doi.org/10.1017/ CBO9780511977848.

Melosh, H.J., Kendall, J., Horgan, B., Johnson, B.C., Bowling, T., Lucey, P.G., Taylor, G.J., 2017. South Pole-Aitken basin ejecta reveal the Moon's upper mantle. Geology 45, 1063-1066. http://dx.doi.org/10.1130/G39375.1.

Moriarty, D.P., Pieters, C.M., 2016. Complexities in pyroxene compositions derived from absorption band centers: Examples from Apollo samples, HED meteorites, synthetic pure pyroxenes, and remote sensing data. Meteorit. Planet. Sci. 51, 207-234. http://dx.doi.org/10.1111/maps.12588.

Moriarty, D.P., Pieters, C.M., 2018. The character of South Pole-Aitken basin: Patterns of surface and subsurface composition. J. Geophys. Res.: Planets 729-747. http: //dx.doi.org/10.1002/2017JE005364.

Moriarty, D.P., Pieters, C.M., Isaacson, P.J., 2013. Compositional heterogeneity of central peaks within the south pole-aitken basin. J. Geophys. Res. E: Planets 118, 2310-2322. http://dx.doi.org/10.1002/2013JE004376.

Ohtake, M., Matsunaga, T., Haruyama, J., Yokota, Y., Morota, T., Honda, C., Ogawa, Y., Torii, M., Miyamoto, H., Arai, T., Hirata, N., Iwasaki, A., Nakamura, R., Hiroi, T., Sugihara, T., Takeda, H., Otake, H., Pieters, C.M., Saiki, K., Kitazato, K., Abe, M., Asada, N., Demura, H., Yamaguchi, Y., Sasaki, S., Kodama, S., Terazono, J., Shirao, M., Yamaji, A., Minami, S., Akiyama, H., Josset, J.L., 2009. The global distribution of pure anorthosite on the Moon. Nature 461, 236-240. http://dx.doi. org/10.1038/nature08317.

Ohtake, M., Takeda, H., Matsunaga, T., Yokota, Y., Haruyama, J., Morota, T., Yamamoto, S., Ogawa, Y., Hiroi, T., Karouji, Y., Saiki, K., Lucey, P.G., 2012. Asymmetric crustal growth on the moon indicated by primitive farside highland materials. Nat. Geosci. 5, 384-388. http://dx.doi.org/10.1038/ngeo1458.

Papanastassiou, D.A., Wasserburg, G.J., 1971a. Lunar chronology and evolution from RbSr studies of Apollo 11 and 12 samples. Earth Planet. Sci. Lett. 11, 37-62. http://dx.doi.org/10.1016/0012-821X(71)90139-7.

Papanastassiou, D.A., Wasserburg, G.J., 1971b. Rbsr ages of igneous rocks from the Apollo 14 mission and the age of the Fra Mauro formation. Earth Planet. Sci. Lett. 12, 36-48. http://dx.doi.org/10.1016/0012-821X(71)90052-5.

Parmentier, E.M., Zhong, S., Zuber, M.T., 2002. Gravitational differentiation due to initial chemical stratification: origin of lunar asymmetry by the creep of dense kreep?. Earth Planet. Sci. Lett. 201, 473-480. http://dx.doi.org/10.1016/S0012821X(02)00726-4.
Pieters, C.M., Boardman, J., Buratti, B., Chatterjee, A., Clark, R., Glavich, T., Green, R., Head, J.W.I., Isaacson, P., Malaret, E., Mccord, T., Mustard, J., Petro, N.E., Runyon, C., Staid, M.I., Sunshine, J.M., Taylor, L., Tompkins, S., Varanasi, P., White, M., 2009. The Moon Mineralogy Mapper $\left(M^{3}\right)$ on chandrayaan-1. Current Sci. 96, 1-6.

Rapp, J.F., Draper, D.S., 2018. Fractional crystallization of the lunar magma ocean : Updating the dominant paradigm. Meteorit. Planet. Sci. 24, 1-24. http://dx.doi. org/10.1111/maps.13086.

Ryder, G., Wood, J.A., 1977. Serenitatis and Imbrium impact melts - Implications for large-scale layering in the lunar crust. Proc. Lunar Planet. Sci. Conf. 65, 5-668.

Shearer, C.K., Hess, P.C., Wieczorek, M.A., Pritchard, M.E., Parmentier, E.M., Borg, L.E., Longhi, J., Elkins-Tanton, L.T., Neal, C.R., Antonenko, I., Canup, R.M., Halliday, A.N., Grove, T.L., Hager, B.H., Lee, D.C., Wiechert, U., 2006. Thermal and magmatic evolution of the Moon. Rev. Mineral. Geochem. 60, 365-518. http: //dx.doi.org/10.2138/rmg.2006.60.4.

Smith, J.V., Anderson, A.T., Newton, R.C., Olsen, E.J., Wyllie, P.J., Crewe, A.V., Isaacson, M.S., Johnson, D., 1970. Petrologic history of the moon inferred from petrography, mineralogy, and petrogenesis of Apollo 11 rocks. In: Proceedings of the Apollo 11 Lunar Science Conference Vol. 1, pp. 897-925.

Smith, D.E., Zuber, M.T., Neumann, G.A., Lemoine, F.G., Mazarico, E., Torrence, M.H., McGarry, J.F., Rowlands, D.D., Head, J.W., Duxbury, T.H., Aharonson, O., Lucey, P.G., Robinson, M.S., Barnouin, O.S., Cavanaugh, J.F., Sun, X., Liiva, P., Mao, D.D., Smith, J.C., Bartels, A.E., 2010. Initial observations from the Lunar Orbiter Laser Altimeter (LOLA). Geophys. Res. Lett. 37, 1-6. http://dx.doi.org/10. 1029/2010GL043751.

Song, E., Bandfield, J.L., Lucey, P.G., Greenhagen, B.T., Paige, D.A., 2013. Bulk mineralogy of lunar crater central peaks via thermal infrared spectra from the Diviner Lunar Radiometer: A study of the Moon's crustal composition at depth. J. Geophys. Res. E: Planets 118, 689-707. http://dx.doi.org/10.1002/jgre.20065.

Spudis, P.D., Davis, P.A., 1986. A chemical and petrological model of the lunar crust and implications for lunar crustal origin. J. Geophys. Res. 91, E84-E90. http://dx.doi.org/10.1029/JB091iB13p00E84.

Stevenson, D.J., 1980. Lunar asymmetry and palaeomagnetism. Nature 287, 520-521. http://dx.doi.org/10.1038/287520a0.

Stuart-Alexander, D.E., 1978. Geologic map of the central far side of the Moon. http://pubs.er.usgs.gov/publication/i948.

Tompkins, S., Pieters, C.M., 1999. Mineralogy of the Lunar Crust - results from clementine. Meteorit. Planet. Sci. 34, 25-41.

Warren, P.H., 1985. The magma ocean concept and lunar evolution. Annu. Rev. Earth Planet. Sci. 13, 201-240. http://dx.doi.org/10.1146/annurev.earth.13.1.201.

Wasson, J.T., Warren, P.H., 1980. Contribution of the mantle to the lunar asymmetry. Icarus 771, 752-771. http://dx.doi.org/10.1016/0019-1035(80)90142-6.

Wieczorek, M.A., Neumann, G.A., Nimmo, F., Kiefer, W.S., Taylor, G.J., Melosh, H.J., Phillips, R.J., Solomon, S.C., Andrews-Hanna, J.C., Asmar, S.W., Konopliv, A.S., Lemoine, F.G., Smith, D.E., Watkins, M.M., Williams, J.G., Zuber, M.T., 2013. The crust of the Moon as seen by GRAIL. Science 339, 671-675. http://dx.doi.org/10. 1126/science.1231530.

Wilhelms, D.E., Howard, K.A., Wilshire, H.G., 1979. Geologic maps of the South side of the Moon. In: US Geol. Surv. Misc. Invest. Ser. I-1162.

Wood, J.A., 1970. Petrology of the lunar soil and geophysical implications. J. Geophys. Res. 75, 6497-6513. http://dx.doi.org/10.1029/JB075i032p06497, http: //doi.wiley.com/10.1029/JB075i032p06497.

Yamamoto, S., Nakamura, R., Matsunaga, T., Ogawa, Y., Ishihara, Y., Morota, T., Hirata, N., Ohtake, M., Hiroi, T., Yokota, Y., Haruyama, J., 2012a. Massive layer of pure anorthosite on the Moon. Geophys. Res. Lett. 39, 1-6. http://dx.doi.org/ 10.1029/2012GL052098.

Yamamoto, S., Nakamura, R., Matsunaga, T., Ogawa, Y., Ishihara, Y., Morota, T., Hirata, N., Ohtake, M., Hiroi, T., Yokota, Y., Haruyama, J., 2012b. Olivine-rich exposures in the South Pole-Aitken Basin. Icarus 218, 331-344. http://dx.doi.org/ 10.1016/j.icarus.2011.12.012.

Yamamoto, S., Nakamura, R., Matsunaga, T., Ogawa, Y., Ishihara, Y., Morota, T., Hirata, N., Ohtake, M., Hiroi, T., Yokota, Y., Haruyama, J., 2016. Global distribution of glass-rich material sites on the Moon. In: Lunar and Planetary Institute Science Conference. pp. 12-13.

Zuber, M.T., Smith, D.E., Lemoine, F.G., Neumann, G.A., 1994. The shape and internal structure of the moon from the clementine mission. Science 266, 1839-1843. http://dx.doi.org/10.1126/science.266.5192.1839. 